\title{
Stress Granules Involved in Formation, Progression and Metastasis of Cancer: A Scoping Review
}

OPEN ACCESS

Edited by:

Feng $\mathrm{He}$

Shanghai University of Traditional Chinese Medicine, China

Reviewed by:

Cai Chen,

Merck, United States

Yanyang Cao,

Washington University School of Medicine in St. Louis, United States

Wenhua Xu,

University of Kentucky, United States

*Correspondence:

Mohammad Taher

Mohammad_823@yahoo.com

Maryam Rezazadeh

Rezazadehm@tbzmed.ac.ir

Specialty section:

This article was submitted to

Molecular and Cellular Oncology,

a section of the journal

Frontiers in Cell and Developmental

Biology

Received: 22 July 2021

Accepted: 25 August 2021

Published: 17 September 2021

Citation:

Asadi MR, Rahmanpour D Moslehian MS, Sabaie H, Hassani M,

Ghafouri-Fard S, Taheri M and Rezazadeh M (2021) Stress Granules

Involved in Formation, Progression and Metastasis of Cancer: A Scoping

Review.

Front. Cell Dev. Biol. 9:745394. doi: 10.3389/fcell.2021.745394
Mohammad Reza Asadi1,2, Dara Rahmanpour², Marziyeh Sadat Moslehian², Hani Sabaie ${ }^{2,3}$, Mehdi Hassani ${ }^{4}$, Soudeh Ghafouri-Fard ${ }^{5}$, Mohammad Taheri6* and Maryam Rezazadeh ${ }^{1,3 *}$

'Molecular Medicine Research Center, Tabriz University of Medical Sciences, Tabriz, Iran, ${ }^{2}$ Student Research Committee, Tabriz University of Medical Sciences, Tabriz, Iran, ${ }^{3}$ Department of Medical Genetics, Faculty of Medicine, Tabriz University of Medical Sciences, Tabriz, Iran, ${ }^{4}$ Student Research Committee, University of Social Welfare and Rehabilitation Sciences, Tehran, Iran, ${ }^{5}$ Department of Medical Genetics, School of Medicine, Shahid Beheshti University of Medical Sciences, Tehran, Iran, ${ }^{6}$ Skull Base Research Center, Loghman Hakim Hospital, Shahid Beheshti University of Medical Sciences, Tehran, Iran

The assembly of stress granules (SGs) is a well-known cellular strategy for reducing stress-related damage and promoting cell survival. SGs have become important players in human health, in addition to their fundamental role in the stress response. The critical role of SGs in cancer cells in formation, progression, and metastasis makes sense. Recent researchers have found that several SG components play a role in tumorigenesis and cancer metastasis via tumor-associated signaling pathways and other mechanisms. Gene-ontology analysis revealed the role of these protein components in the structure of SGs. Involvement in the translation process, regulation of mRNA stability, and action in both the cytoplasm and nucleus are among the main features of SG proteins. The present scoping review aimed to consider all studies on the effect of SGs on cancer formation, proliferation, and metastasis and performed based on a six-stage methodology structure and the PRISMA guideline. A systematic search of seven databases for qualified articles was conducted before July 2021. Publications were screened, and quantitative and qualitative analysis was performed on the extracted data. Go analysis was performed on seventy-one SGs protein components. Remarkably G3BP1, TIA1, TIAR, and YB1 have the largest share among the proteins considered in the studies. Altogether, this scoping review tries to demonstrate and provide a comprehensive summary of the role of SGs in the formation, progression, and metastasis of cancer by reviewing all studies.

Keywords: stress granules, cancer, progression, metastasis, G3BP1, TIA1, TIAR, YB1

\section{INTRODUCTION}

In 1988, dense cytoplasmic bodies formed under stress in chicken embryonic fibroblasts were named stress granules (SGs) (Collier et al., 1988). SGs are dense bodies that, under stress, are composed of RNA and proteins and are located in the cytosol (Gutierrez-Beltran et al., 2015). Ribonucleoproteins appear under different stresses, and with the end of stress, their number decreases and is limited to SGs being disassembled (Kedersha et al., 2013). Within a specific 
classification of stresses based on a study in 2008, two categories can be presented: Type I stresses preferentially induce SG formation, which includes hypoxia, heat shock, and arsenic, whereas type II stresses especially activate stress-responsive MAPK cascades, which include X-rays and genotoxic drugs like methyl methanesulphonate (MMS), etoposide (Arimoto et al., 2008). In response to this diversity of stress, the cell pursues an evolutionary strategy that leads to the formation of SGs (Jevtov et al., 2015). Stopping the translation process due to stress builds an extensive repository of components of SGs, translation initiation factors, RNA binding proteins, and non-RNA binding proteins constitute the protein components, and mRNA, which is a non-protein part (Cao et al., 2020). With the release of stress and the end of translational inhibition, the SGs disassemble, and the mRNA makes its way to the translating polysomes (Aulas et al., 2017; Khong and Parker, 2018).

Decision points are a term that can be attributed to SGs even though no specific function has been assigned to them so far (Buchan and Parker, 2009). The decision point for the two components of SGs is the mRNA trapped in their structure and the proteins that make them up (Decker and Parker, 2012). mRNA can take three pathways, remain in the structure of SGs and be stored, resume translation from the structure of released SGs, or move toward degradation. Interestingly, factors such as low translatability, increased coding region length, and untranslated region can also positively increase the likelihood of mRNA being present in the SG structure (Aulas et al., 2017). The major protein component of SGs, which is composed of RNA-binding proteins, can also have two specific domains, Prion Like Domains (PLDs) and Intrinsically Disordered Domains (IDDs), which have the potential to form protein aggregates (Gilks et al., 2004). Low complexity sequence is one of the main features of IDDs and PLDs domains identified by single amino acid repeats with polar residues such as tyrosine, serine, asparagine, and glutamine (Malinovska et al., 2013). These domains can cause SGs to assemble during electrostatic interactions by enhancing the liquid-liquid phase separation (Lin et al., 2015). When protein-overloaded RNAs (especially proteins with IDDs and PLDs domains) dispersed in the cytoplasm or nucleoplasm (soluble phase) coalesce into a concentrated state, liquid-liquid phase separation occurs (condensed phase). During this condensed phase, the highly concentrated RNAs and RNA-binding proteins (RBPs) act as a single organelle with liquid-like properties and high interactions to form SGs (Yang et al., 2020).

Stress granules, with their strong presence, have established themselves in a wide range of diseases, and many studies have shown the extent of these diseases, including cancer (Buchan, 2014), neurodegenerative diseases (Asadi et al., 2021), autoimmune diseases (Johnson et al., 2016), and many other diseases. Among these, cancer can be discussed from three different perspectives: the formation of cancer and tumorigenesis, cancer survival and metastasis, invasion, and progression of cancer cells (Hamidi and Ivaska, 2018). Cancer cells respond to mutant oncogenes by over-proliferation and over-cellular potency, so it makes perfect sense to face more stress (Urra et al., 2016; El-Naggar and Sorensen, 2018). On the other hand, adapting to stresses caused by over-proliferation is also a characteristic of cancer cells (Sharma et al., 2016), which generally in cells with normal conditions lead to death, but in cancerous conditions, the cell quickly adapts survives (Senft and Ronai, 2016). Remarkably, cancer uses the ownership and usability of SGs against stress from the cell to benefit from better tumorigenesis and progression (Grabocka and Bar-Sagi, 2016; Protter and Parker, 2016). Thus, SGs have been introduced as a cancer cell stress-adaptive strategy for a wide range of tumorrelated stresses, including proteotoxic stress, oxidative stress, and osmotic stress for the cell (Somasekharan et al., 2015; Grabocka and Bar-Sagi, 2016). In addition to affecting cell proliferation, pro-tumorigenic hyperactivation signaling pathways increase the formation of SGs, which prolongs the life of cancer cells and leads to tumor cell proliferation. On the other hand, the prominent role of SGs in resistance to anticancer drugs is a powerful lever of cancer (Cruz et al., 2019; Herman et al., 2019). So far, many studies have been done on the structure, components, and derivatives of SGs in cancer. As a systematic scoping review, the present study revised all studies on SGs to summarize all aspects of their effects on cancer, from its formation to its progression and metastasis. It also provided a table of eligible studies that included major findings, major methods, and, most importantly, the SGs protein components examined further by gene ontology analysis.

\section{MATERIALS AND METHODS}

\section{The Review's Overall Framework}

The method proposed by Arksey and O'Malley (2005) served as the basis for this article's strategy. Levac et al. (2010) and Colquhoun et al. (2014) later improved on this strategy. The 5-step framework is followed in this review, which includes the following steps, respectively: Classifying the research question, Search plan, Study selection, Data collection, Data summary, and synthesis of results. The sixth and final step is consultation, which is not covered in this article. The Preferred Reporting Items for Systematic Reviews and Meta-Analysis Extension for Scoping Reviews (PRISMA-ScR) Checklist is used to consider and observe two crucial aspects of clarity and transparency while writing the article (Tricco et al., 2018).

\section{Classifying the Research Question}

The overall main research question developed is defined as:

'What studies have been done on SGs in formation, progression and metastasis in cancer?'

'What are the results and findings of these studies?'

It should be noted that general and comprehensive questions are considered to include significant studies.

\section{Search Plan}

Pubmed, Embase, Scopus, Cochrane, Google Scholar, Web of Science, and ProQuest were searched to access the publications. A date, language, subject, or publication type restriction was not applied to the search. Review publications were also revised 
to eliminate the possibility of related articles being ignored. We almost used the following search query for our searches in cancer: "cancer*” OR "neoplasm*" OR "cyst*" OR "carcinoma*” OR “adenocarcinoma*” OR "neurofibroma*” OR “tumor*” OR "tumor*” OR "malign*." The search keywords and search results in each database are listed in medical subject heading $(\mathrm{MeSH})$ for the PubMed database, and emtree for the Embase database are also used correctly in the search. The last search was led on July 15, 2021. The references were managed using EndNote X8.1.

\section{Study Selection}

Cancer studies involving SGs in humans, cell lines, and animal model studies were screened from the publications found during the search. All types of publications, including journal articles, conference presentations, Erratum, conference abstracts, and reports, were screened. Two reviewers (MA and DR) independently completed the screening in two stages (first only title and abstracts, second full-text). The titles and abstracts of the articles were reviewed at this stage using the Inclusion and Exclusion criteria listed below. The full text of the articles was reviewed, and irrelevant articles were removed, ensuring that the articles were entirely consistent with the research questions. Any discrepancies in agreement with the third person's opinion were resolved.

\section{Inclusion Criteria}

I. studies include: SGs in the formation, progression, and metastasis of cancers (any cancer) (all human studies/animal studies/cell culture studies).

II. Articles in English only.

III. Original studies.

\section{Exclusion Criteria}

I. Studies of SGs in diseases other than cancer.

II. Studies on the effect of SGs on cancer treatment (anticancer medications, chemotherapy, and radiotherapy).

III. Languages other than English.

IV. Studies that are not original.

V. Studies have used bioinformatics and impractical methods to study stress granules.

\section{Charting the Data}

Following the completion of the final articles that answer the research questions, the data-charting was created to organize the study variables using the following headings: author's name, year of publication, country, type of study, human samples, animal models, cell lines, SGs protein components, methods, major findings, and references. Two reviewers (MA and DR) extracted data from articles using charts separately.

\section{Data Summary and Synthesis of Results}

The findings from the publications presented in tables and charts were subjected to quantitative and qualitative analysis. A descriptive numerical summary of the study's scope, nature, and distribution was reviewed in the quantitative analysis section. The presented data was affirmed on the broader context suggested by Levac et al. (2010), in a narrative review, in the qualitative analysis section.

\section{RESULTS}

There were 1029 results from a keyword search across seven databases. Meanwhile, thirteen additional records were discovered through other sources and added to the total number of articles. Endnote software found and deleted 501 duplicate records, bringing the total number of articles to 541. Following a review of the article titles and abstracts, 117 articles that addressed the research question were chosen. At this point, 56 articles were included in Supplementary Table 1 for the charting data stage after reviewing the full text of 117 articles. Figure 1 shows the step-by-step procedure for selecting eligible articles and studies. Eligible studies were published between 2008 and 2021. Supplementary Table 1 was created to rank studies from top to bottom in order to provide faster access to article division based on study frequency. The percentage of various studies is shown in Figure 2. Meanwhile, the majority of studies, about $66 \%$ of studies, are dedicated to cell culture studies only (Baguet et al., 2007; Miyoshi et al., 2007; Arimoto et al., 2008; EisingerMathason et al., 2008; Goulet et al., 2008; Busà et al., 2010; Gottschald et al., 2010; Guo et al., 2010; Kalra et al., 2010; Nikpour et al., 2011; Taniuchi et al., 2011a,b, 2014; Park et al., 2012; Fournier et al., 2013; Pizzo et al., 2013; Thedieck et al., 2013; Chang et al., 2014; Kano et al., 2014; Podszywalow-Bartnicka et al., 2014; Yuan et al., 2014; Krisenko et al., 2015; Liu et al., 2015; Somasekharan et al., 2015; Szafron et al., 2015; ValentinVega et al., 2016; Weeks et al., 2016; Narayanan et al., 2017; Wall and Lewis, 2017; Takayama et al., 2018; Haghandish et al., 2019; Heberle et al., 2019; Kashiwagi et al., 2019; Mazloomian et al., 2019; Cui et al., 2020; Do et al., 2020; Brown et al., 2021). After that, cell culture, animal and human sample studies with $12.5 \%$ of studies (Grabocka and Bar-Sagi, 2016; Coppin et al., 2017; Wang et al., 2018; Choi et al., 2019; Vellky et al., 2020; Zhang et al., 2021; Zhao et al., 2021), respectively, cell culture and human sample studies with $10 \%$ of the total studies (Andersson et al., 2008; Wen et al., 2012; Cougot et al., 2014; Bartkowiak et al., 2015; Chiou et al., 2017; Lin et al., 2019), cell culture and animal study in 9\% of the total studies (Meng et al., 2012; Gupta et al., 2017; Morettin et al., 2017; Chen H.-Y. et al., 2018; Wang et al., 2021), had a share of this study. Among these, only one study used just human samples in the study's design (Zheng et al., 2019). Human cancer samples used in the studies, respectively, include pancreatic cancer sample (Wen et al., 2012; Grabocka and Bar-Sagi, 2016; Coppin et al., 2017), gastric cancer sample (Lin et al., 2019; Zhao et al., 2021), breast cancer sample (Her2 positive or negative) (Cougot et al., 2014; Zhang et al., 2021), prostate cancer sample (Vellky et al., 2020), Renal Cell Carcinoma samples (Wang et al., 2018), Bone marrow aspiration and blood samples (Bartkowiak et al., 2015), and non-small-cell lung carcinoma samples (Zheng et al., 2019). The contribution of cell lines used in the studies is summarized in Figure 2. There are 83, which is given as a bar-plot diagram with the corresponding percentage in Figure 2A; the other in this figure represents cell lines that have 


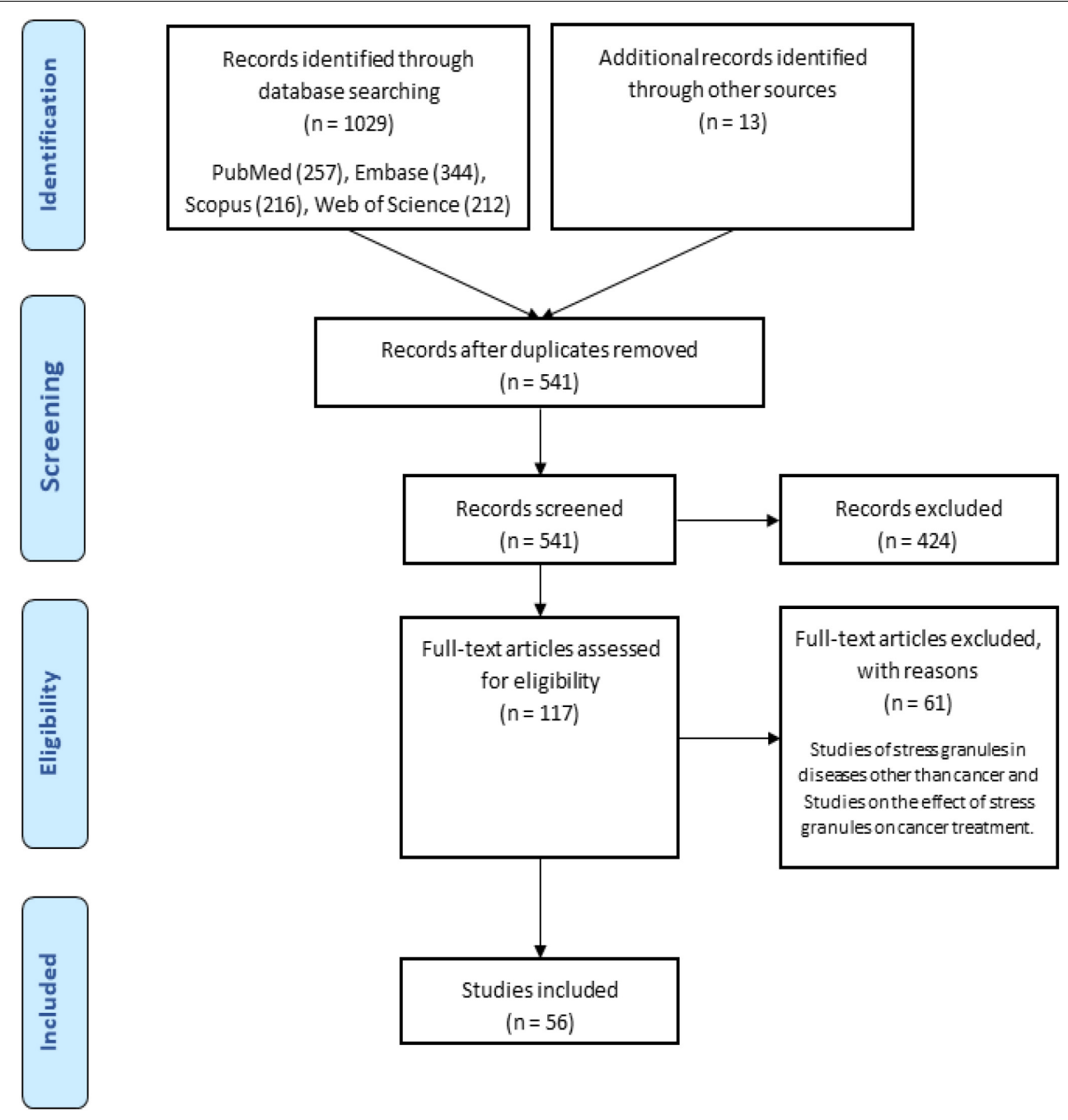

FIGURE 1 | Flow chart of search strategy based on PRISMA flow diagram.

only been used once in studies. Figure 3 illustrates the amount of each SGs protein component examined in all studies. The highest rates are related to G3BP1 with $12.5 \%$, TIA1 with $7.5 \%$, TIAR with 5\%, and YB1 with 4.5\%. Only the most important methods and tests are mentioned due to the large number of methods and tests used in these studies. The distribution of studies is limited to twelve countries, with the United States accounting for the largest share with 13 studies, followed by China and Canada with ten each, Japan with eight, France with three, Netherlands, South Korea, Poland, Germany, and Italy with two each, and Iran and Sweden with one each.

\section{DISCUSSION}

\section{Cancer, Formation, Progression, and Metastasis}

Oncogene activation and tumor suppressor gene (TSG) inactivation can result in uncontrolled cell proliferation, known as cancer (Weiss, 2020). The tumor structure consists of cells that carry changes in the genes that regulate growth and differentiation (Croce, 2008). Oncogenes are involved in the induction of cell proliferation. Changes in these genes can range from developing new oncogenes to the overexpression of common oncogenes that were previously proto-oncogenes. On the other hand, TSGs inhibit cell proliferation by acting in the reverse pathway (Zhu et al., 2015). The features that help cancer cells to progress can be both distinct and complementary and be necessary to the proliferation, survival, and spread of tumor cells which include replication in proliferative signaling pathways, Evasion of growth inhibitors, resistance to programmed cell death, induction of angiogenesis, reprogramming of metabolic mechanisms for anaerobic glycolysis, support for cell proliferation in hypoxia and immune system evasion with The goal to remove these cells in the early stages of progression (Hanahan and Weinberg Robert, 2011).

Different types of cancers based on cellular origin in a common classification can be divided into four main categories: 


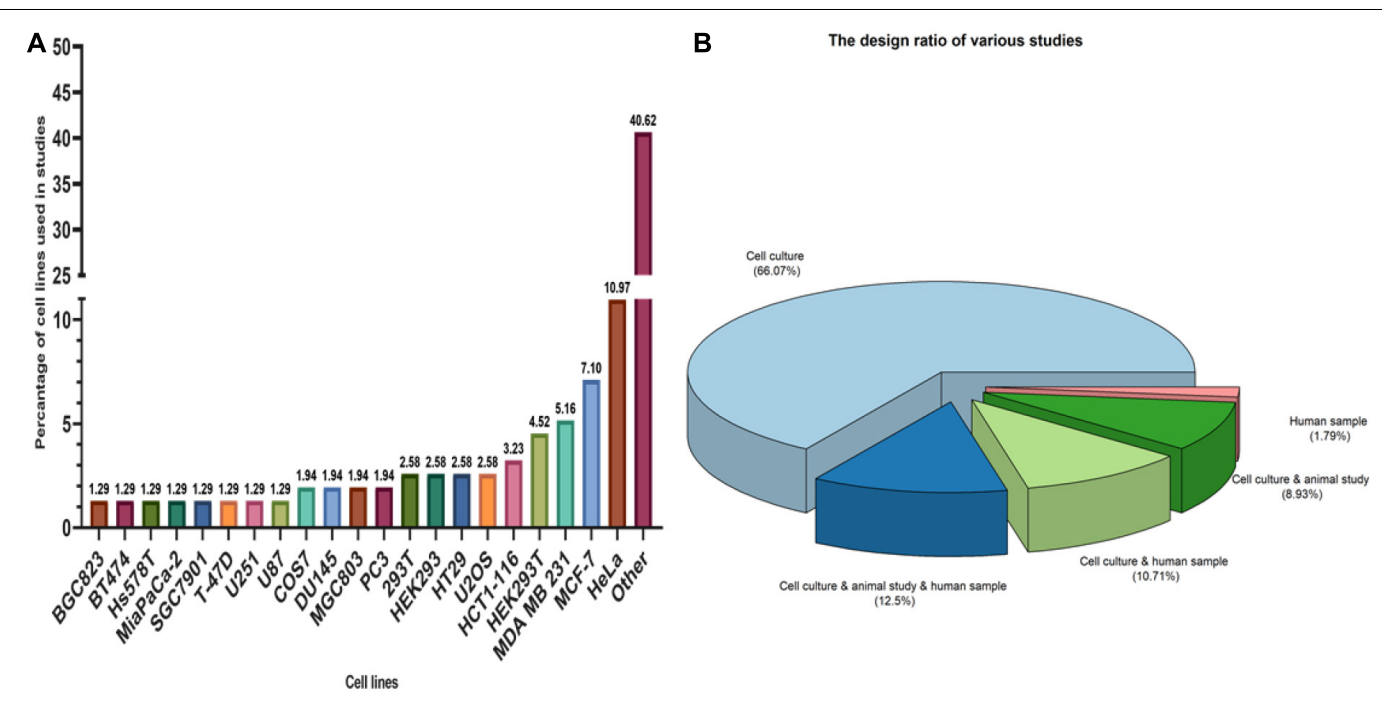

FIGURE 2 | Type of studies and participation of cell lines in studies. (A) The longer the bar, the greater the use of cell lines in studies. The figure shows that Hela cells, MCF-7 and MDA MB 231, respectively, had the highest participation among cell lines. OTHER in this section includes cell lines that have been used only once in studies that include: A341, A498, A549, ACHN, 32D mouse progenitor cells, ALL/MIK, AsPC1, Ba-F3/CL1, BCaP, BC-M1, Bladder carcinoma cell line, BxPc3, CAPAN-1, Capan2, Cos-1, CT2A, DG75, DLD1, F470, HCT-8, Hec50, Hepatocellular carcinoma cells (HCC), HFF-1, HGC-27, HPDE, Hs700T, HT-1080, human B lymphoma cells, human PDAC cell line, Jurkat, K562, KrasG12D HPDE cells, Ku812, LAPC4 cell, LC-M1, LNCaP, MCa-PSTC, MKN45, MNNG, MY, Mycoplasma, N2a, NCl-H508, NCl-H747, NCM460, Panc-1, pancreatic cancer cells, PC-E1, RH-30 cells, S2-013, SNB19, SNUC-1, SW480, T98, TOM-1, U118, U343, uroepithelial cell, VCaP, VMRC-LCD, WEHI-3, yeast, and YMB-1. (B) Among the types of studies, cell culture studies were more frequent, followed by cell culture, animal study, and human samples studies with the highest number with $12.5 \%$ in study design.

carcinoma, sarcoma, melanoma, lymphoma, and leukemia (Carbone, 2020). Tumors caused by cancer can be divided into two categories based on their characteristics: malignant or benign (Kalkat et al., 2017). One of the main characteristics of malignant tumors is the ability to metastasize (Tarin, 2011). Metastasis is the ability to enable cancer cells to spread to other parts of the body. Almost all tumors have the potency to metastasize (Brown et al., 2017). The blood and lymphatic system are the two main bases for metastasis, with either required for metastasis (Alitalo and Detmar, 2012). The stages of metastasis can be summarized in the steps of local invasion, intravasation by blood/lymphatic circulation, and extravasation in new tissue and proliferation and angiogenesis, respectively (Figure 4; Shelton et al., 2010). Meanwhile, the stresses that enter the cancer cells push the situation in a direction to dysregulate the equilibrium of SGs and use SGs as an advantage in cancer conditions to benefit cancer cells (Anderson et al., 2015; Do et al., 2020).

\section{A Precise Glance at Stress Granules: Canonical or Non-canonical Stress Granules}

There are two ways to form SGs. The path, which the SGs formation is eIF $2 \alpha$-dependent, and eIF $2 \alpha$ is involved in forming SGs leads to the formation of canonical SGs (Bhardwaj et al., 2019). Stress affects eIF $2 \alpha$, mediates serine 51 phosphorylation, and initiates the production of canonical SGs by stopping the development of the translation initiation complex due to lack of GDP / GTP exchange for eIF2 $\alpha$-GTP tRNA-met (Dang et al., 2006). Four stress-related kinases have the ability to phosphorylate the alpha subunit, including PKR under viral infections, PERK due to ER stress, HRI kinase (heme-regulated inhibitor) under osmotic stress and oxidative stress, and GCN2 kinase activated under amino acid starvation (Aulas et al., 2017; Wolozin and Ivanov, 2019). Inhibition of proteasomes that can target these kinases by MG132 and lactacystin can lead to the continuation of these kinases' effect and the production of canonical SGs (Mazroui et al., 2007).

eIF4A, eIF4E, and eIF4G are also components of the eIF4F complex, which detects the $5^{\prime}$ cap structure on mRNA, which can, if changed or not appropriately functioned, halt translation at the pre-initiation stage and produce SGs called non-canonical which are entirely independent of eIF $2 \alpha$ (Mokas et al., 2009). If any of the eIF4F components are inhibited or interfere with their performance, the translation's beginning is hindered. Pateamine A, silvestrol, and hypuristanol may result in the production of non-canonical SGs by degrading eIF4A activity (Mokas et al., 2009), affecting eIF4E (Fujimura et al., 2012), and the destructive effect of the virus on the eIF4G structure (Yang et al., 2018; Figure 5).

In general, canonical or noncanonical SGs increase the number of SGs when the cell is under stress and agitated the equilibrium between SGs assembly and disassembly (Hofmann et al., 2021). Among these, by relieving stress, the formed SGs move toward disassembly. The most critical process that stops due to stress and causes SGs to develop is the translation process. Therefore, resuming translation by relieving stress causes SGs to disassemble (Baumann, 2021). Disassembling SGs occurs in several stages, beginning with the RNA leaving the SG structure and entering the suspended translation process. This 


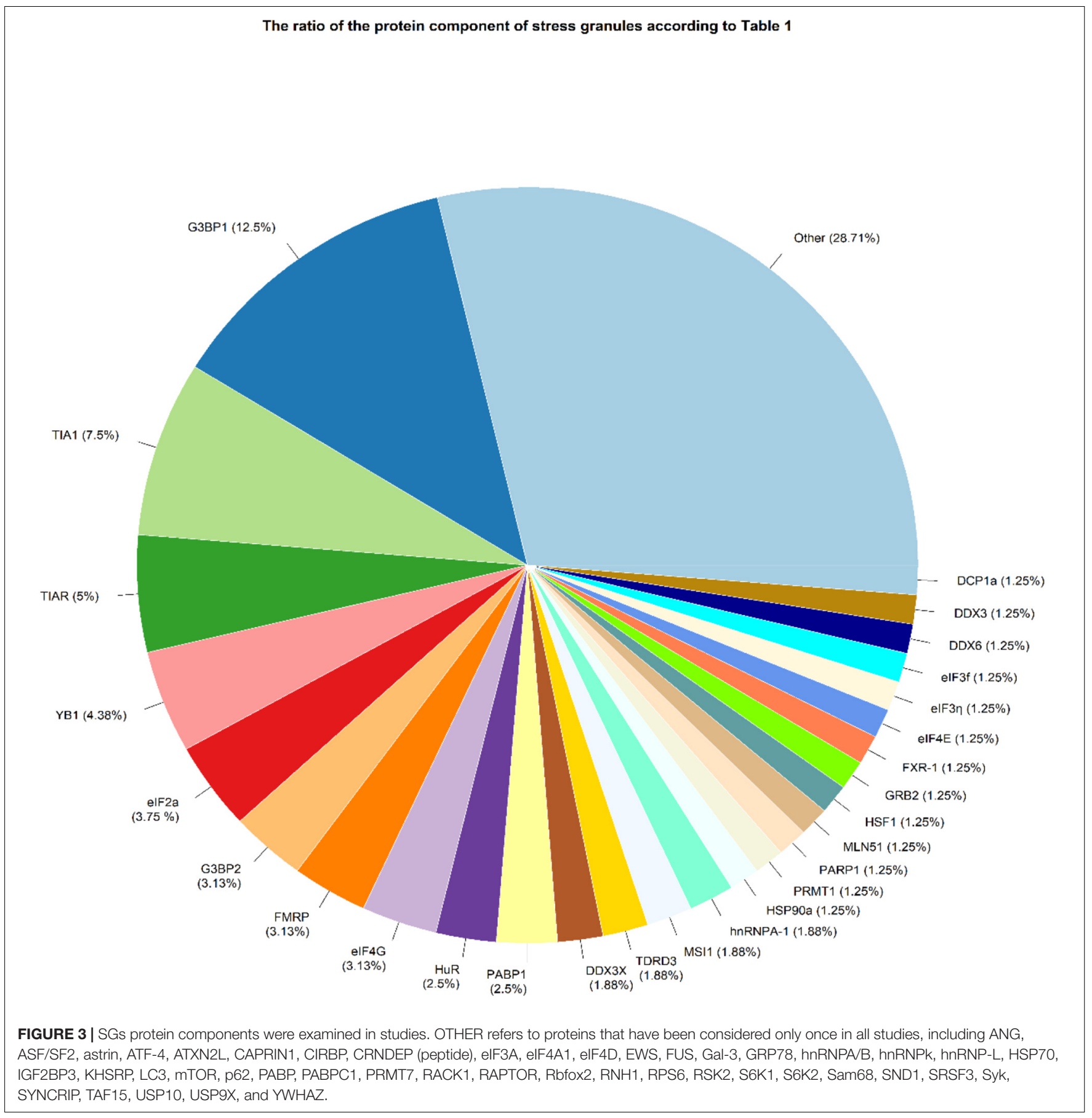

RNA release is accompanied by structural instability of the SG, leading to the decomposition of a complete SG structure into smaller core structures that continue disassembling or clearance by autophagy, the final number of SGs decreases (Wheeler et al., 2016).

\section{Stress Granules Assembly Through Cancer Signaling Pathways}

Stress that affects cancer cells is not the only cause of SGs formation. Dysregulation of specific signaling pathways associated with inhibition of translation or protein-protein interactions can also induce the formation of SGs (Thedieck et al., 2013; Heberle et al., 2019). The mammalian target of rapamycin (mTOR) is one of the most critical pathways with a considerable contribution in inducing the formation of SGs. mTOR forms two separate complexes, both functionally and structurally, which include mTOR1 and mTOR2. mTOR1 is responsible for regulating cell growth and metabolism, while mTOR2 regulates cell proliferation and survival (Wolfson and Sabatini, 2017; Unni and Arteaga, 2019). mTOR plays an essential role in many 


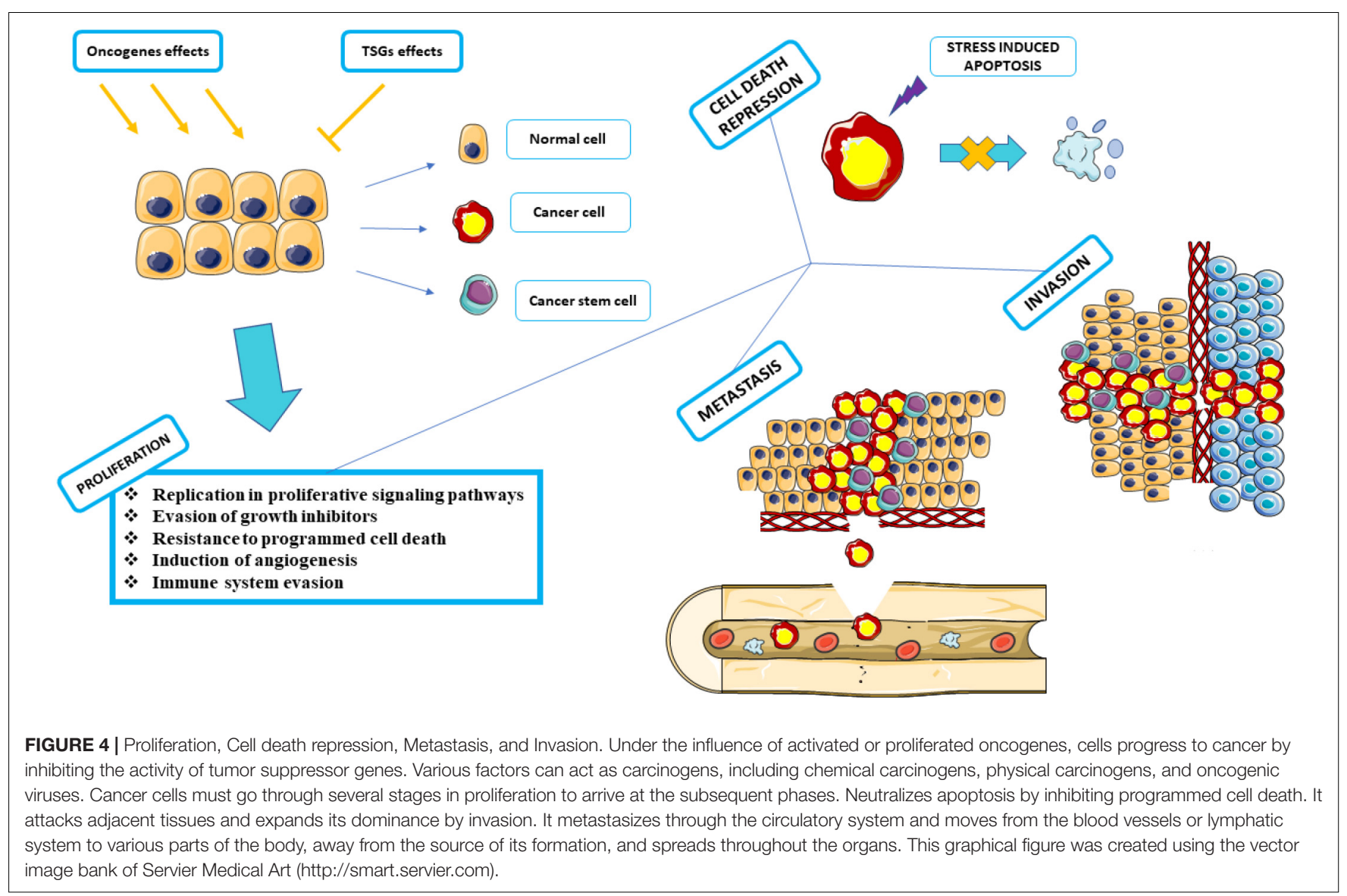

signaling pathways, including PI3K/AKT, TSC1/TSC2/Rheb, and AMPK (Dowling et al., 2010). In abnormally activated mTOR tumor cells, it sends growth, metastasis, and invasion signals to other tissues (Hsieh et al., 2012). Among these, up-regulation of the PI3K / AKT / mTOR pathway is one of the main pathways in many malignant tumors (Lim et al., 2015). Assembly of SGs can also be involved in mTORC-related pathways. One of the ways SGs are formed is through the mTORC pathway. On the other hand, inhibition of mTORC1 by Torkinib can lead to a destruction in the formation of SGs, or cell depletion of eIF4G1 or eIF4E, which can neutralize the SG-associated antiapoptotic p21 pathway (Fournier et al., 2013). Raptor is part of the structure of mTORC1, which can be associated with SGs (Takahara and Maeda, 2012). Meanwhile, astrin, as a negative regulator of mTORC1, causes raptor localization in the structure of SGs. This localization inhibits mTORC1 over-activation and inhibits apoptosis (Thedieck et al., 2013). mTORC1 activation mediated by PI3K and P38 hierarchically leads to an increase in the SGs assembling, affecting the raptor (Heberle et al., 2019).

Impressively, it should be noted that SGs and mTORC1 play a role in bilateral regulation. SGs participate in this regulation by incorporating mTORC1 components, including raptor and $\alpha, \beta$, and $\gamma$ subunits (Hofmann et al., 2012; Wippich et al., 2013; Heberle et al., 2019). Conversely, inhibition of mTORC1 is also associated with increased SGs production. mTORC1 inhibits the effect of 4E-BP on eIF4E by phosphorylation and inactivation of eIF4E-BP during the PI3K-mTOR kinase cascade, forming the eIF4F complex, which is responsible for identifying the cap structure at the $5^{\prime} \mathrm{mRNA}$ end, thus initiating the translation phase. By inhibiting mTORC1 under stress, eIF4E-BP remains active and inhibits the formation of the eIF4F complex, halting the translation process in the initial stage. This process predisposes the SGs to form by leaving the PIC (pre-initiation complex) on the mRNA and acting as a nest (Frydryskova et al., 2016; Wolozin and Ivanov, 2019). The point to consider is the SGs-mTORC1 interactions, whether the rise or reduction in SG assembly overlaps with the inhibition or activity of mTORC1. Eventually, cancer cells inhibit the conduction of cancer cells to apoptosis by inhibiting hyper-activation of mTORC1 by SGs (Wippich et al., 2013).

RTK-RAS is one of the other essential pathways involved in cancer and is recognized by the cancer genome atlas (TCGA) as the most highly modified oncogenic network in cancer (SanchezVega et al., 2018). twenty to thirty percent of all human cancers have RAS (KRAS-HRAS-NRAS) alteration (Cerami et al., 2012). KRAS is common in pancreatic adenocarcinomas and colorectal cancer, NRAS in melanoma, thyroid cancer, and leukemia (Gao et al., 2013). Cancer cells are under different stresses and must be adapted. However, the mutant RAS protein is the equipment of these cells and equips the cell against tumor-associated stresses to satisfy stress adaptation (Tao et al., 2014; Yang et al., 2018). Remarkably, the presence of SGs was observed in mutant KRAS 


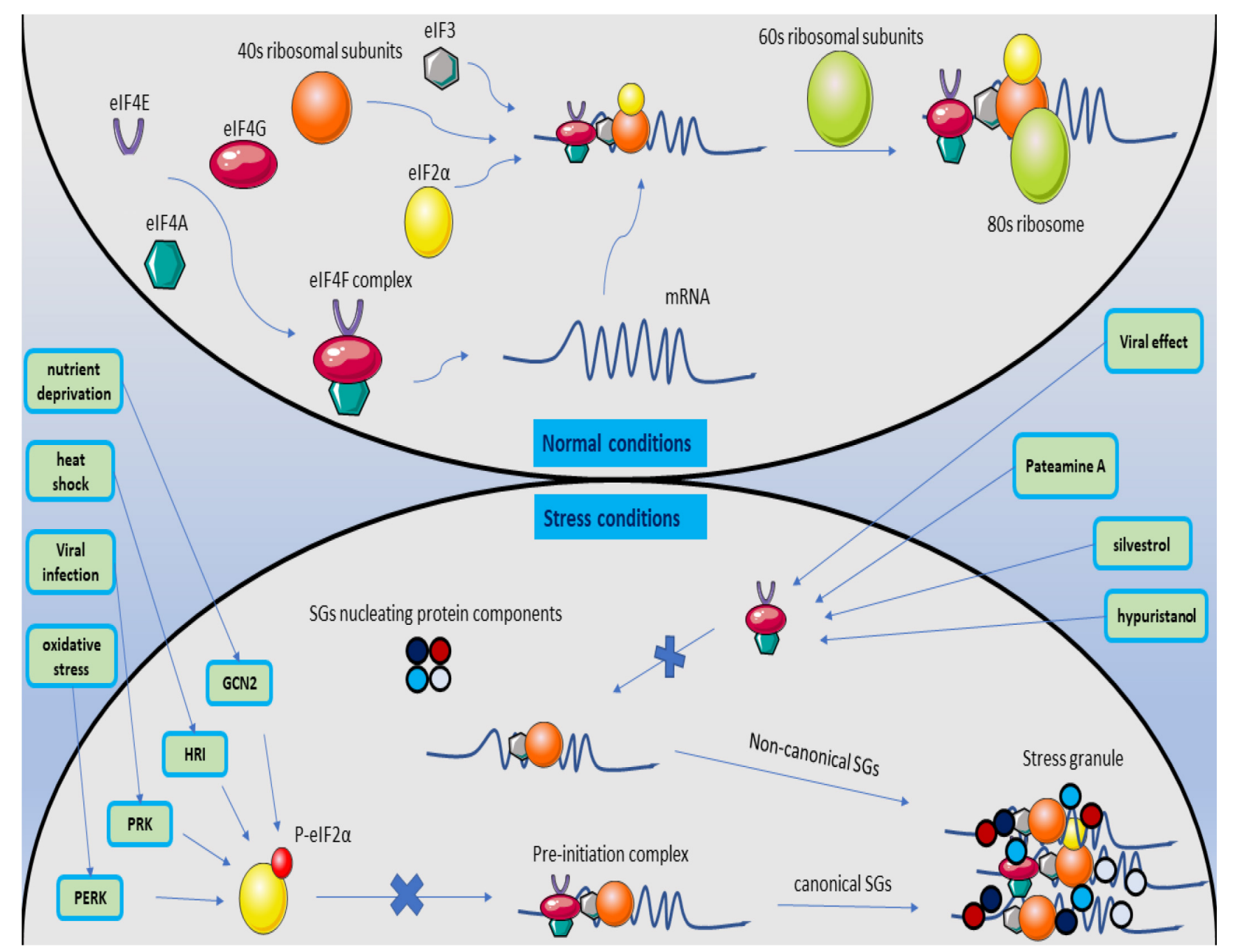

FIGURE 5 | Magnification of canonical and non-canonical stress granules. Under normal conditions, the translation process begins with forming the elF4F structure and identifying the $5^{\prime}$ cap structure on the mRNA. The pre-initiation complex is formed by joining elF3, the ribosomal $40 S$ subunit, and non-phosphorylated elF2a with the initial tRNA. Then, with the 60S ribosome subunit, the ribosome structure is completed, and the translation process is followed. When the cell is stressed, it activates PERK, PRK, HRI, and GCN2 kinases, causes phosphorylation of elF2a, and prevents the binding of P-elF2a to the PIC structure. The exact process creates the structure of canonical SGs. If the stress on the cell proceeds by inhibiting the formation of the elF4F structure by affecting its subunits, the formation of non-canonical SGs is followed by merging the SGs nucleating protein components in the elF2a independent manner.

pancreatic cancer cells as opposed to normal cells. SGs are among the primary responses to stimulation in the survival of mutant KRAS pancreatic cancer cells compared to KRASWT cancer cells. KRAS mutants induce the formation of SGs by up-regulating 15 -Deoxy-delta $(12,14)$-prostaglandin J (2) (15d-PGJ2) through downstream effector molecules, RALGDS, and RAF (Grabocka and Bar-Sagi, 2016). 15d-PGJ2 targets cystine 264 in eIF4A, destroying its interaction with eIF4G, the interaction required for the translation process. The effect on this interaction inhibits translation and leads to the formation of SGs (Kim et al., 2007). Instead, mutant KRAS with up-regulation of the nuclear factor erythroid 2-related factor 2 (NRF2) causes rearrangement of glutamine metabolic pathways in tumor cells (Hamada et al., 2021). In addition to its effect on glutamine metabolic pathways, NRF2 is involved in the 15d-PGJ2 effect on the SGs formation (Mukhopadhyay et al., 2020). In the absence of glutamine, an increase in GIRGL LncRNA levels in the cell forms a complex between GLS1 mRNA and CAPRIN1, which induces SGs and inhibits GLS1 mRNA translation by increasing the LLPS process in CAPRIN1, allowing the cancer cell to survive (Wang et al., 2021). Meanwhile, KRAS causes up-regulation of 15d-PGJ2 by increasing the expression of Cyclooxygenase- 2 (COX-2). Increasing the levels of 15d-PGJ2 leads to an increase in the assembly of SGs by affecting eIF4A (Qiang et al., 2019). On the other hand, sorafenib, an anticancer medication that increases the production of SGs along the GCN2 / eIF2a pathway, is highly dependent on COX-2 expression. COX-2 is colocalized in the structure of SGs, and inhibition of COX-2 by its inhibitor, celecoxib, results in increased response to sorafenib treatment (Chen W. et al., 2018).

When the cell experiences different types and many stresses, the involvement of autophagy in stress-responsive 

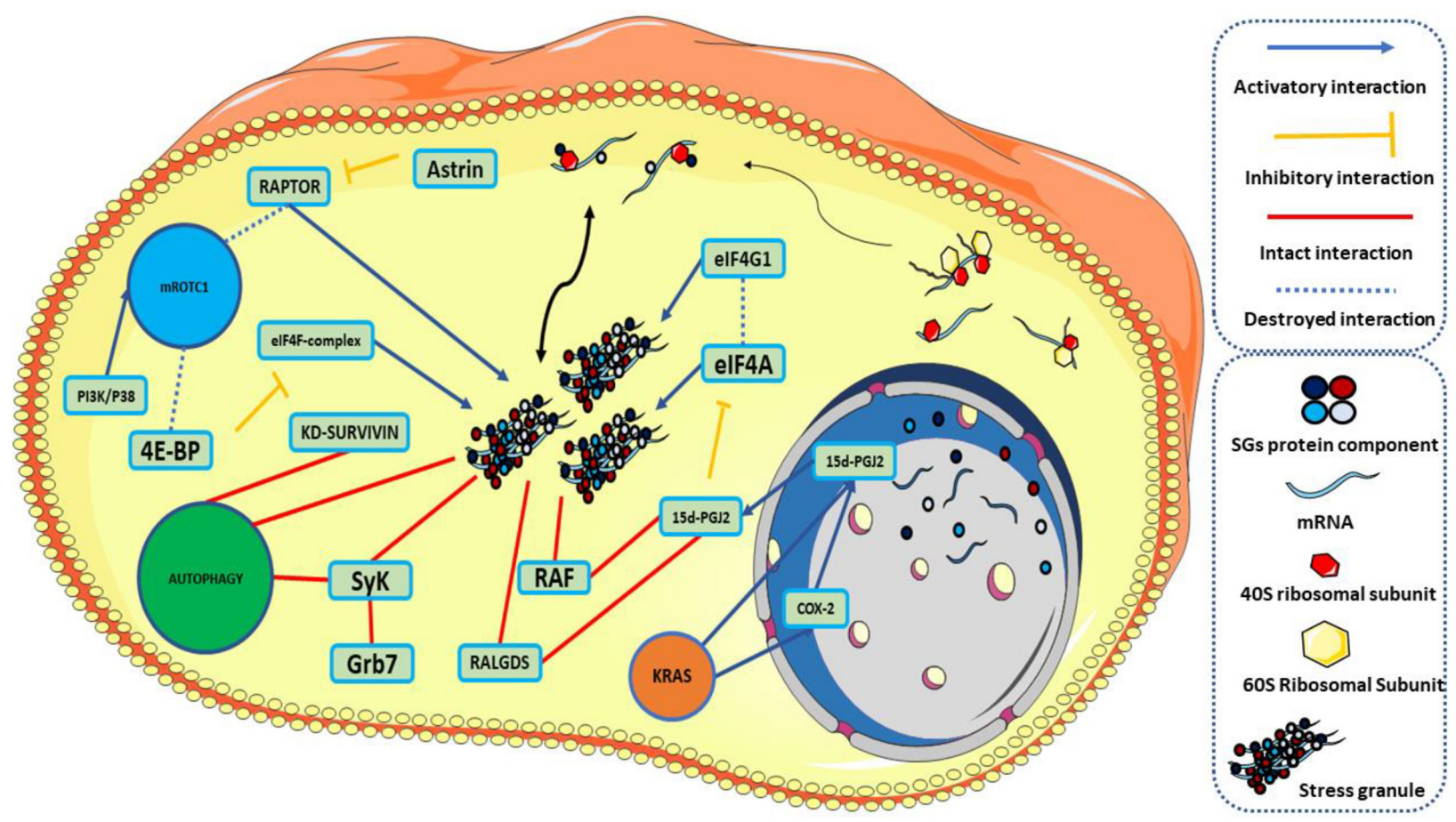

FIGURE 6 | Traces of stress granules in signaling pathways. Under natural conditions, stress granules are assembled and disassembled under an equilibrium. KRAS causes up-regulation of 15d-PGJ2 directly or through COX-2. On one side of the pathway, 15d-PGJ2 interacts with RALGDS and RAF to form SGs. 15d-PGJ2, on the other hand, targets elF4A, destroys its connection to elF4G, stops the translation process, and leads to the formation of SGs. Knocking down survivin is associated with an increase in the number of SGs and activation of autophagy. SyK phosphorylation by Grb7 localizes SyK in the structure of SGs and activates autophagy. Localization of RAPTOR in the SGs structure by up-regulation of astrin leads to an increase in the production of SGs. On the other hand, inhibition of mTORC1 inhibits phosphorylation of 4E-BP and the formation of elF4F complex and causes the formation of SGs. 15d-PGJ2: 15-Deoxy-delta (12,14)-prostaglandin $J(2)$, KD-survivin: knocking Down-Survivin. This graphical figure was created using the vector image bank of Servier Medical Art (http://smart.servier.com).

mechanisms is inevitable. Autophagy is a metabolic and homeostasis-maintaining intracellular recycling system and cellular self-degradation process that has evolved over time. Autophagy is activated in response to various cellular stresses, such as nutrient deficiency, organelle damage, and abnormal protein accumulation (Mizushima and Levine, 2010). Autophagy inhibits cancer cell survival and induces cell death, suppressing tumorigenesis in cancer cells. Conversely, autophagy can aid tumorigenesis by encouraging cancer cell proliferation and tumor growth (Salminen et al., 2013). survivin is an antiapoptotic protein that inhibits caspase activity (Altieri, 1994). Silencing survivin increases the production of SGs and has the ability to activate the Autophagy signaling pathway as an alternative to survival in hepatocellular carcinoma cells. After the cell is released from stress, autophagy can accompany the cell's survival (Chang et al., 2014). Syk a cytoplasmic kinase, which depending on the type of cancer cells, can appear on both the anticancer and cancer promoter fronts (Krisenko and Geahlen, 2015). Grb7 phosphorylates syk in the tyrosine residue under stress that induced SGs formation and recruited in the structure of SGs. When the stress is relieved, this recruitment promotes the formation of autophagosomes and the clearance of SGs from the cell, enhancing the cells' ability to withstand the stress stimulus (Figure 6; Krisenko and Geahlen, 2015).

\section{Stress Granules Involved in Cancer Characteristics}

\section{Proliferation}

In general, the effect of SGs on proliferation goes through two paths-effect on cell cycle and proliferation regulating factors and effect on transcripts of these factors. SGs play an essential role in keeping cells in the cell cycle progression and preventing cells from entering cell death phases. Specific protein 1 (SP1) is a transcription factor with a significant role in regulating SGnucleating proteins such as HuR, TIA1 / TIAR, and G3BP1. Interestingly, depleting of the cell of SP1 leads to cell death (Mahboubi and Stochaj, 2017). HuR and CIRP are colocalized in the SGs, and CIRP plays a pivotal role in HUR's positive regulation. On the other hand, HuR increases the level of cyclinE1 in breast cancer cells (Guo et al., 2010). When constitutively overexpressed in the mouse mammary gland, Cyclin E1 can act as a true oncogene, driving the formation of tumors, though with low penetrance (10\%) and long-latency (Bortner and Rosenberg, 1997). Overexpression of cyclin E1 increases the proportion of cells in the $\mathrm{S}$ phase, which leads to increased $\mathrm{Rb}$ phosphorylation and cell proliferation in many cancer cell line models (Hwang and Clurman, 2005). Cancer stem cells (CSCs) are a small subset of tumor cells that play a vital role in the proliferation phase due to their reproducibility, differentiation, and tumorigenesis 
(Samanta and Kar, 2021). Musashi1 (MSI1) is closely related to CSCs with many regulatory interactions as part of the structure of SGs. In colorectal cancer, MSI1 promotes the development of CD44 cancer stem cells (Chiou et al., 2017). MSI1 participates in the PKR/eIF2 cancer stem cell-enhancing machinery and promotes proliferation (Chen H.-Y. et al., 2018). RSK2, one of the protein components of SGs, is released from the structure of SGs under the influence of mitogen and has a direct effect on cyclin D1 and follows by proliferation (Eisinger-Mathason et al., 2008). CRNDEP, a polypeptide produced by the CRNDP gene, is also part of the structure of SGs and is present in highly proliferative tissues with increased expression compared to other tissues (Szafron et al., 2015).

The effect on the transcript of factors and effectors in the proliferation process can be pursued in two ways:

I. The effect of SG components on the transcripts of factors involved in proliferation.

II. Localization of transcripts of factors involved in proliferation as an RNA component in the structure of SGs.

Rbfox 2 is a protein responsible for regulating the mRNA stability of many genes and acts as an important member in alternative splicing (Lovci et al., 2013). Rbfox 2 in the structure of SGs affecting the mRNA of Rb1, a tumor suppressor, and reducing its stability and expression, increases the proliferation process in cancer cells. Remarkably, by isolating Rbfox 2 from the structure of SGs, resveratrol inhibited its effect on $\mathrm{Rb} 1$ and effectively reduced the proliferation of cancer cells (Choi et al., 2019). Y-box binding protein-1 (YB-1) is one of the multifunctional proteins that have a role as a regulator in translation and transcription, and by regulating cell cycle progression at G1 / S plays an essential role in the growth and proliferation of tumor cells (Fujiwara-Okada et al., 2013). short RNA antisense to dicer1 ( $\operatorname{shad1)}$ can be colocalized with YB-1 in the structure of SGs and plays a vital role in regulating the proliferation of cancer cells, including prostate cancer cells, by affecting the expression of YB-1, DLX2, and IGFBP2 (Liu et al., 2015). Impressively, only $15 \%$ of all cell mRNAs are colocalized in the SG structure (Khong et al., 2017), which, this mRNA component of SGs through gene enrichment analysis, primarily identified as proto-oncogene transcripts with high enrichment (Namkoong et al., 2018).

MUC4 is an explicit marker of epithelial tumors, and its expression is linked to the degree of differentiation in various cancers. MUC4 has emerged as a specific dysplasia marker expressed in the early dysplastic lesions prior to several malignancies, including incurable pancreatic cancer (Chakraborty et al., 2008). MUC4 mRNA in cancer cells is stabilized by Gal-3, which is found in the structure of hnRNPL-containing RNA granules. Gal-3 acts as a non-classic RBP in the structure of SGs by interacting with hnRNP-L (Coppin et al., 2017). Under ER stress, BCR-ABL1 mediated TIAR activation. TIAR is a component of cytoplasmic SGs that affects the ARE site in BRCA1 mRNA and can result in its down-regulation in BCR-ABL1 leukemia, which leads to genomic instability. HuR influenced BRCA1 translation and mRNA stability positively
(Podszywalow-Bartnicka et al., 2014). It should be noted that the oncogenic tyrosine kinase BCR-ABL is also localized in the structure of SGs, and the formation of granular structure is necessary for the activity of ABL kinase and $\mathrm{N}$-terminal region of BCR (Kashiwagi et al., 2019).

\section{Cell Death Repression}

Many studies have examined the role of SGs in Cell death repression and inhibition of apoptosis, and the vital role of SGs in these processes has been well established. According to studies in Cell death repression, SGs also use their structural capacity and change the cell's fate by including essential components in this pathway. Among these, SGs are involved in the sequestration of pro-apoptotic proteins and the inclusion of mRNAs of important apoptotic mediators and their protection and involvement in the regulatory mechanisms of reactive oxygen species (ROS), which are further reviewed in this study. Raptor sequestration, part of the mTORC1 structure in the structure of SGs due to astrin and its role in inhibiting apoptosis, was mentioned (Thedieck et al., 2013). S6K1 and S6K2 are among the influential factors on mTORC1. S6K1 under mild arsenite stress and S6K2 under mild and acute arsenite stress are localized in the structure of SGs. RSKS1, the ortholog of S6K1 and S6K2 in C.eleganse, localized under stress in the structure of SGs and hindered apoptosis through inhibiting mTORC1 hyperactivation (Sfakianos et al., 2018).

Under oxidative stress conditions, RACK1 interaction is inhibited by localization in the structure of SGs with MTK, a MAPK kinase required for apoptosis due to P38 / JNK activation (Arimoto et al., 2008). MSI1 is up-regulated as SGs component in bladder carcinoma cell lines relative to normal uroepithelial cells and inhibits apoptosis by targeting mRNA of essential genes, including P21 CIP1(Nikpour et al., 2011). On the other hand, Macrophage-inhibitory cytokine-1 (MIC1), one of the proapoptotic proteins associated with the pathogenesis of many cancers under ER stress, activates the ERK1 / 2 signaling pathway, which stabilizes MIC1 mRNA in the structure of SGs (Park et al., 2012). USP9X acts as one of the most critical proteins in inhibiting apoptosis (Kushwaha et al., 2015). Ubiquitin Specific Peptidase 9 X-Linked (USP9X) and Tudor Domain Containing 3 (TDRD3) are colocalized in the structure of SGs. The presence of TDRD3 is essential to protect USP9X against de-ubiquitination. Knockdown TDRD3 inhibits the presence of USP9X in the structure of SGs and increases cellular apoptosis (Narayanan et al., 2017). Meanwhile, Increased expression of USP10 in prostate cancer cells in interaction with G3BP2 inhibits the P53 signaling pathway and causes a specific carcinogenic effect along the USP10 / G3BP2 / P53 pathway (Takayama et al., 2018).

\section{Metastasis and Invasion}

The distinguishing feature between invasion and metastasis is the ability of the metastasis to use the circulatory system or lymphatic system, which spreads cancer cells to tissues farther from the source. In contrast, invasion is defined as the penetration of cancer cells into neighboring tissues (Krakhmal et al., 2015). Metastasis is also a response to the stress that cancer cells undergo, and SGs are used as cellular equipment in this response. 


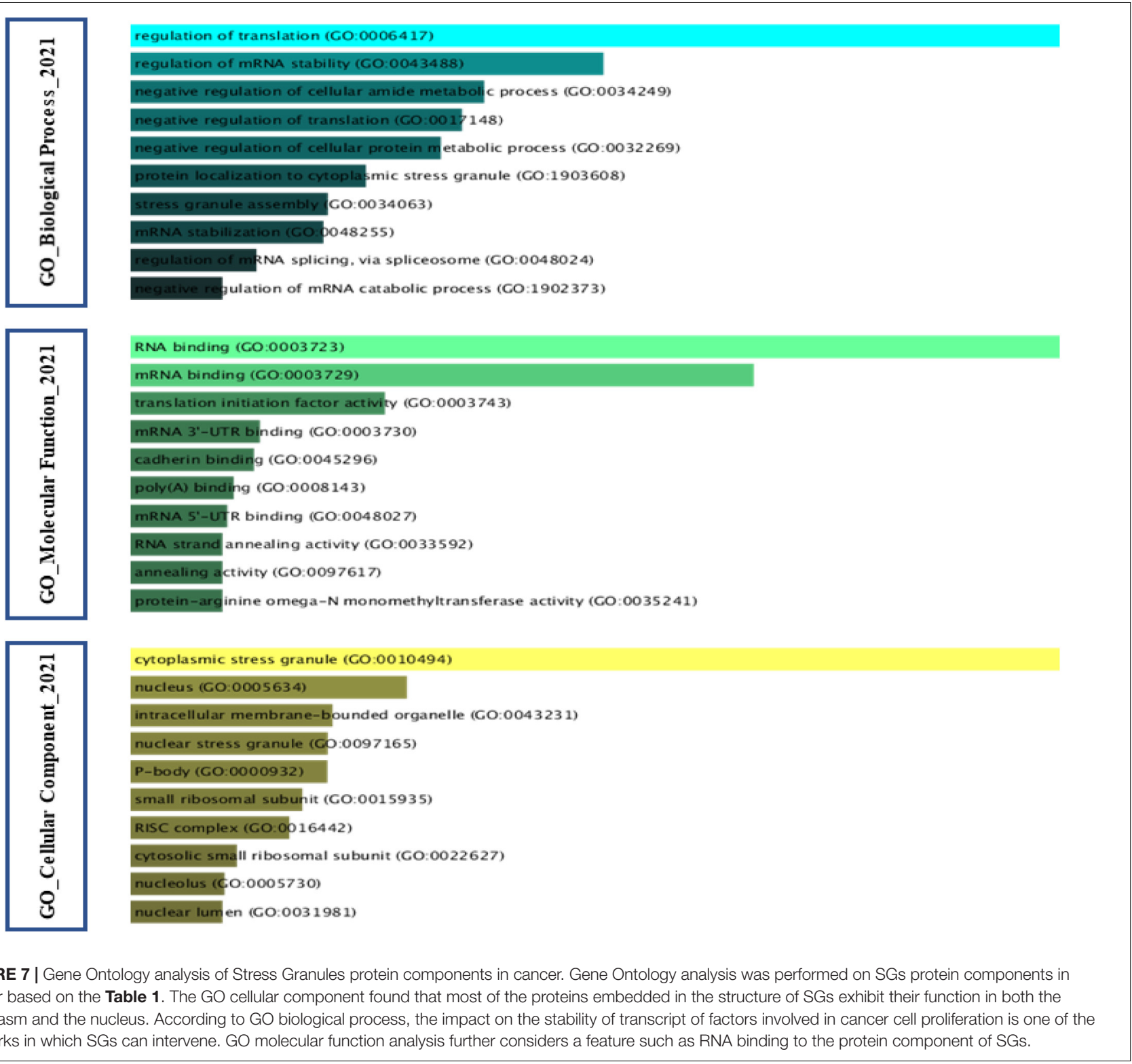

SGs allow healthy cells to stop their translation process under stress and keep important mRNAs in the SG structure intact. The exact process in cancer cells gives survival under challenging conditions and paves the way for the later stages of cancer. Remarkably, cells with a higher potential for metastasis also carry more SGs (Somasekharan et al., 2015).

Targeting the formation of SGs by drug inhibition through the NRF2 transcription factor destroys the invasive and metastatic capacity of pediatric sarcoma to the extent that targeting SGs is suggested as a treatment for pediatric brain tumors (Delaidelli et al., 2018). TDRED3, in addition to its role in inhibiting apoptosis by interacting with USP9X (Narayanan et al., 2017), also plays a vital role in determining the invasive capacity of breast cancer cells. Undergoing chemotherapy, TDRD3 is targeted at the structure of SGs. CELL DEPLETION TDRD3 inhibits the progression and invasion of cancer cells
TABLE 1 | Stress classifications inducing canonical SGs assembly.

\begin{tabular}{lll}
\hline Stress characteristics & SGs inducing target & References \\
\hline oxidative stress & elF2 $\alpha$ (PERK) & Palangi et al., 2017 \\
ER stress & elF2 $\alpha$ (PERK) & Wang et al., 2019 \\
Viral infection & elF2 $\alpha($ PKR $)$ & García et al., 2006 \\
nutrient deprivation & elF2 $\alpha($ GCN2) & Wek et al., 1995 \\
UV irradiation & elF2 $\alpha($ GCN2) & Deng et al., 2002 \\
heat shock & elF2 $\alpha($ HRI) & Lu et al., 2001 \\
\hline
\end{tabular}

(Morettin et al., 2017). On the other hand, increased invasion of gastric cancer cells can occur in response to oxaliplatin through ATXN2L up-regulation, known as the regulator of SGs, with the effect of EGF along with the PI3 / AKT signaling pathway (Lin et al., 2019). G3BP1, as a nucleator member in the structure of SGs, is responsible for a significant part of the 
SG-dependent metastasis and invasion process (Taniuchi et al., 2011a,b, 2014; Somasekharan et al., 2015; Wang et al., 2018). RAS-GTPase-activating protein $\mathrm{SH} 3$ domain-binding protein 1 is overexpressed in many head, neck, prostate, breast, and colon tumors (Xiong et al., 2019). G3BP1 also causes tumor progression and metastasis in renal cell carcinoma cells by over-expression along the IL6 / G3BP1 / STAT3 pathway (Wang et al., 2018). Remarkably, the reduction of G3BP1 levels through YB-1 globally acetylation by MS-275 treatment reduces the sarcoma metastasis and reduces the premetastatic activity of the G3BP1 factor (El-Naggar and Sorensen, 2018). In addition, non-small cell lung cancer patients with clinical stages II and III had higher G3BP1 and YB1 protein expression than those with stage I. Furthermore, G3BP1 protein expression was positively correlated with YB1 and pAKT (Zheng et al., 2019).

Binder of Arl Two (BART) is also one of the main factors regulating and reducing metastasis and invasion of pancreatic cancer cells. The N-terminal part of G3BP can down-regulate BART post-transcriptionally and increases metastatic activity (Taniuchi et al., 2011b). CD24 regulates G3BP endoribonuclease activity and its effect on BART, so the CD24 / G3BP / BART pathway is essential in metastasis (Taniuchi et al., 2011a).

\section{Chemotherapy Resistance}

Another aspect that cancer cells use to benefit from SGs is the response to treatment and chemotherapy. The equilibrium between SGs assembling and disassembling versus chemotherapy in cancer cells is entangled, and this disequilibrium tends to increase the number of SGs. The common denominator of most chemotherapeutic agents is summarized in eIF2 $\alpha$ phosphorylation (Gao et al., 2019). Four stress-associated kinases are considered to phosphorylate eIF2 $\alpha$ (Aulas et al., 2017; Wolozin and Ivanov, 2019). Sorafenib and bortezomib are two FDA-approved drugs that are each used to treat specific cancers. Sorafenib is a Raf1 / Mek / Erk kinase inhibitor used to treat hepatocellular carcinoma (Adjibade et al., 2015), thyroid carcinoma (Lin et al., 2021), and renal carcinoma (Chen W. et al., 2018). Remarkably, treatment with sorafenib induces phosphorylation of the eIF2 alpha subunit by PERK and increases the formation of SGs (Adjibade et al., 2015). On the other hand, bortezomib, which is used for the chemotherapy of multiple myeloma, also induces eIF $2 \alpha$ phosphorylation by HRI and follows an increase in the number of SGs (Fournier et al., 2010). Bortezomib-induced SGs move in the opposite direction of the effect of bortezomib as an anticancer drug by increasing the degradation of p21 transcripts that play a role in increasing apoptosis (Gareau et al., 2011).

Among the chemotherapeutic agents, there are many cases in which phosphorylates eIF2 $\alpha$ through a specific kinase, including sorafenib (Adjibade et al., 2015), lapatinib (Adjibade et al., 2020), arsenite (Zou et al., 2012), thapsigargin (Doan et al., 2015) via PERK, 5-Fu via PKR (Longley et al., 2003), MG132 via GCN2 (Mazroui et al., 2007), and bortezomib via HRI (Schewe and Aguirre-Ghiso, 2009). Increased production of SGs is accompanied by an increase in mechanisms that can resist chemotherapy, including the regulation of apoptosis and autophagy (Chang et al., 2014), the facilitation of ABC family expression (Unworth et al., 2010), and the regulation of malignant cell stemness (Chiou et al., 2017). Meanwhile, according to studies, targeting SGs as anti-stress granule therapy along with conventional chemotherapy can create a new perspective for cancer treatment and has the potential to be recognized through further studies as a new treatment.

\section{Gene-Ontology Analysis of Stress Granules Protein Components}

A noteworthy point at the end is that gene-ontology analysis of the proteins of SGs that have been extracted based on the studies in Table 1. Regulation of translation has the maximum rate of the physiological function of these proteins concerning other proteins in a biological network. Bring to an end in the translation initiation stage is the central mechanism that underlies the formation of SGs. Likewise, one of the capabilities that SGs provide to cancer cells is the protection or inclusion of transcription factors involved in proliferation as part of their constituent structure, which is confirmed by the GO-biological process. Interestingly, these proteins also play a crucial role in the regulation of mRNA stability by these factors. On the other hand, the function of these proteins must be in the direction of the duty they perform, which has so far been closely related to the RNA molecule. The GO-Molecular function confirmed RNA binding in various forms, including RNA binding, mRNA binding, and mRNA $3^{\prime}$ and $5^{\prime}$-UTR binding. According to the GO cellular component, most of the proteins embedded in the SGs structure have functions in both the cytoplasm and the nucleus (Figure 7).

\section{CONCLUSION}

Stress granules have become one of the main instruments of cancer cells to deal with stress. Due to their structural capacities, SGs provide cancer cells with the ability to go through the most critical stages in their process. The role of mTOR and RAS pathways in cancer has been proven in many studies. The involvement of SGs and playing a pivotal role in these pathways in different cancers are identified as a common point. On the other hand, the effect of SGs on cell cycle regulating factors and essential factors involved in proliferation in cancer cells is used as a biased mechanism. Utilizing the capacities of SGs in the process of cell death repression and the presence of more SGs in cells prone to metastasis accompanies cancer in the following essential phases. There have been many studies on SGs in cancer formation, progression, and metastasis. In this study, the aim was to provide a comprehensive review to conclude this matter. Overall, this study could pave the way for further studies on SGs in cancers and provide a roadmap to guide these studies.

\section{AUTHOR CONTRIBUTIONS}

MT, MR, and SG-F wrote the draft and revised it. MA, HS, DR, $\mathrm{MM}$, and $\mathrm{MH}$ collected the data and designed the tables and figures. All authors read and approved the submitted version. 


\section{FUNDING}

This research protocol was approved and supported by the Molecular Medicine Research Center, Tabriz University of Medical Sciences (grant number: 67116).

\section{REFERENCES}

Adjibade, P., Simoneau, B., Ledoux, N., Gauthier, W. N., Nkurunziza, M., Khandjian, E. W., et al. (2020). Treatment of cancer cells with Lapatinib negatively regulates general translation and induces stress granules formation. PLoS One 15:e0231894. doi: 10.1371/journal.pone.0231894

Adjibade, P., St-Sauveur, V. G., Quevillon Huberdeau, M., Fournier, M. J., Savard, A., Coudert, L., et al. (2015). Sorafenib, a multikinase inhibitor, induces formation of stress granules in hepatocarcinoma cells. Oncotarget 6, 4392743943. doi: 10.18632/oncotarget.5980

Alitalo, A., and Detmar, M. (2012). Interaction of tumor cells and lymphatic vessels in cancer progression. Oncogene 31, 4499-4508.

Altieri, D. C. (1994). Molecular cloning of effector cell protease receptor-1, a novel cell surface receptor for the protease factor Xa. J. Biol. Chem. 269, 3139-3142.

Anderson, P., Kedersha, N., and Ivanov, P. (2015). Stress granules, P-bodies and cancer. Biochim. Biophys. Acta 1849, 861-870.

Andersson, M. K., Ståhlberg, A., Arvidsson, Y., Olofsson, A., Semb, H., Stenman, G., et al. (2008). The multifunctional FUS, EWS and TAF15 protooncoproteins show cell type-specific expression patterns and involvement in cell spreading and stress response. BMC Cell Biol. 9:37. doi: 10.1186/1471-21 21-9-37

Arimoto, K., Fukuda, H., Imajoh-Ohmi, S., Saito, H., and Takekawa, M. (2008) Formation of stress granules inhibits apoptosis by suppressing stress-responsive MAPK pathways. Nat. Cell Biol. 10, 1324-1332. doi: 10.1038/ncb1791

Arksey, H., and O'Malley, L. (2005). Scoping studies: towards a methodological framework. Int. J. Soc. Res. Methodol. 8, 19-32.

Asadi, M. R., Sadat Moslehian, M., Sabaie, H., Jalaiei, A., Ghafouri-Fard, S., Taheri, M., et al. (2021). Stress granules and neurodegenerative disorders: a scoping review. Front. Aging Neurosci. 13:650740. doi: 10.3389/fnagi.2021.650740

Aulas, A., Fay, M. M., Lyons, S. M., Achorn, C. A., Kedersha, N., Anderson, P., et al. (2017). Stress-specific differences in assembly and composition of stress granules and related foci. J. Cell Sci. 130, 927-937. doi: 10.1242/jcs. 199240

Baguet, A., Degot, S., Cougot, N., Bertrand, E., Chenard, M. P., Wendling, C., et al. (2007). The exon-junction-complex-component metastatic lymph node 51 functions in stress-granule assembly. J. Cell Sci. 120(Pt 16), 2774-2784. doi: $10.1242 /$ jcs.009225

Bartkowiak, K., Kwiatkowski, M., Buck, F., Gorges, T. M., Nilse, L., Andreas, A., et al. (2015). Disseminated tumor cells persist in the bone marrow of breast cancer patients through sustained activation of the unfolded protein response. Cancer Res. 75, 5367-5377. doi: 10.1158/0008-5472.CAN-14-3728

Baumann, K. (2021). mRNA translation in stress granules is not uncommon. Nat. Rev. Mol. Cell Biol. 22:164.

Bhardwaj, M., Leli, N., Koumenis, C., and Amaravadi, R. (2019). Regulation of autophagy by canonical and non-canonical ER stress responses. Semin. Cancer Biol. 66, 116-128.

Bortner, D. M., and Rosenberg, M. P. (1997). Induction of mammary gland hyperplasia and carcinomas in transgenic mice expressing human cyclin E. Mol. Cell. Biol. 17, 453-459. doi: 10.1128/MCB.17.1.453

Brown, D., Smeets, D., Székely, B., Larsimont, D., Szász, A. M., Adnet, P. Y., et al. (2017). Phylogenetic analysis of metastatic progression in breast cancer using somatic mutations and copy number aberrations. Nat. Commun. 8:14944.

Brown, N., Vergara, A., Whelan, A., Guerra, P., and Bolger, T. (2021). Medulloblastoma-associated mutations in the DEAD-box RNA helicase DDX3X/DED1 cause specific defects in translation. J. Biol. Chem. 296:100296. doi: $10.1016 /$ j.jbc.2021.100296

Buchan, J. R. (2014). mRNP granules. Assembly, function, and connections with disease. RNA Biol. 11, 1019-1030. doi: 10.4161/15476286.2014.972208

Buchan, J. R., and Parker, R. (2009). Eukaryotic stress granules: the ins and outs of translation. Mol. Cell 36, 932-941. doi: 10.1016/j.molcel.2009.11.020

\section{SUPPLEMENTARY MATERIAL}

The Supplementary Material for this article can be found online at: https://www.frontiersin.org/articles/10.3389/fcell.2021. 745394/full\#supplementary-material

Busà, R., Geremia, R., and Sette, C. (2010). Genotoxic stress causes the accumulation of the splicing regulator Sam68 in nuclear foci of transcriptionally active chromatin. Nucleic Acids Res. 38, 3005-3018. doi: 10.1093/nar/gkq004

Cao, X., Jin, X., and Liu, B. (2020). The involvement of stress granules in aging and aging-associated diseases. Aging Cell 19:e13136.

Carbone, A. (2020). Cancer classification at the crossroads. Cancers 12:980. doi: $10.3390 /$ cancers 12040980

Cerami, E., Gao, J., Dogrusoz, U., Gross, B. E., Sumer, S. O., Aksoy, B. A., et al. (2012). The cBio cancer genomics portal: an open platform for exploring multidimensional cancer genomics data. Cancer Discov. 2, 401-404. doi: 10. 1158/2159-8290.CD-12-0095

Chakraborty, S., Jain, M., Sasson, A. R., and Batra, S. K. (2008). MUC4 as a diagnostic marker in cancer. Expert Opin. Med. Diagn. 2, 891-910.

Chang, Y. J., Li, L. T., Chen, H. A., Hung, C. S., and Wei, P. L. (2014). Silencing survivin activates autophagy as an alternative survival pathway in HCC cells. Tumor Biol. 35, 9957-9966. doi: 10.1007/s13277-014-2257-6

Chen, H.-Y., Lin, L.-T., Wang, M.-L., Tsai, K.-L., Huang, P.-I., Yang, Y.-P., et al. (2018). Musashi-1 promotes chemoresistant granule formation by PKR/eIF2 $\alpha$ signalling cascade in refractory glioblastoma. Biochim. Biophys. Acta Mol. Basis Dis. 1864, 1850-1861. doi: 10.1016/j.bbadis.2018.02.017

Chen, W., Zhao, X., Cao, W., Diao, W., and Guo, H. (2018). MP72-03 sorafenibtriggered stress granules promote resistance in renal cancer cells by recruiting anti-apoptotic cyclooxygenase 2. J. Urol. 199, e952-e953.

Chiou, G. Y., Yang, T. W., Huang, C. C., Tang, C. Y., Yen, J. Y., Tsai, M. C., et al. (2017). Musashi-1 promotes a cancer stem cell lineage and chemoresistance in colorectal cancer cells. Sci. Rep. 7:2172. doi: 10.1038/s41598-017-02057-9

Choi, S., Sa, M., Cho, N., Kim, K., and Park, S.-H. (2019). Rbfox2 dissociation from stress granules suppresses cancer progression. Exp. Mol. Med. 51:49. doi: 10.1038/s12276-019-0246-y

Collier, N. C., Heuser, J., Levy, M. A., and Schlesinger, M. J. (1988). Ultrastructural and biochemical analysis of the stress granule in chicken embryo fibroblasts. J. Cell Biol. 106, 1131-1139. doi: 10.1083/jcb.106.4.1131

Colquhoun, H. L., Levac, D., O’Brien, K. K., Straus, S., Tricco, A. C., Perrier, L., et al. (2014). Scoping reviews: time for clarity in definition, methods, and reporting. J. Clin. Epidemiol. 67, 1291-1294

Coppin, L., Vincent, A., Frénois, F., Duchêne, B., Lahdaoui, F., Stechly, L., et al. (2017). Galectin-3 is a non-classic RNA binding protein that stabilizes the mucin MUC4 mRNA in the cytoplasm of cancer cells. Sci. Rep. 7:43927. doi: $10.1038 /$ srep 43927

Cougot, N., Daguenet, E., Baguet, A., Cavalier, A., Thomas, D., Bellaud, P., et al. (2014). Overexpression of MLN51 triggers P-body disassembly and formation of a new type of RNA granules. J. Cell Sci. 127(Pt 21), 4692-4701. doi: 10.1242/ jcs. 154500

Croce, C. M. (2008). Oncogenes and cancer. N. Engl. J. Med. 358, 502-511.

Cruz, A., Verma, M., and Wolozin, B. (2019). The pathophysiology of tau and stress granules in disease. Adv. Exp. Med. Biol. 1184, 359-372.

Cui, B. C., Sikirzhytski, V., Aksenova, M., Lucius, M. D., Levon, G. H., Mack, Z. T., et al. (2020). Pharmacological inhibition of DEAD-Box RNA Helicase 3 attenuates stress granule assembly. Biochem. Pharmacol. 182:114280. doi: 10.1016/j.bcp.2020.114280

Dang, Y., Kedersha, N., Low, W. K., Romo, D., Gorospe, M., Kaufman, R., et al. (2006). Eukaryotic initiation factor 2alpha-independent pathway of stress granule induction by the natural product pateamine A. J. Biol. Chem. 281, 32870-32878. doi: 10.1074/jbc.M606149200

Decker, C. J., and Parker, R. (2012). P-bodies and stress granules: possible roles in the control of translation and mRNA degradation. Cold Spring Harb. Perspect. Biol. 4:a012286.

Delaidelli, A., Negri, G., Cho, B., Minaker, S., El-Naggar, A., Hukin, J., et al. (2018). PDTM-02. Stress granules are induced by oxidative stress in pediatric brain tumors and predict poor outcome. Neuro Oncol. 20, vi203-vi204. 
Deng, J., Harding, H. P., Raught, B., Gingras, A. C., Berlanga, J. J., Scheuner, D., et al. (2002). Activation of GCN2 in UV-irradiated cells inhibits translation. Curr. Biol. 12, 1279-1286. doi: 10.1016/s0960-9822(02)01037-0

Do, T. Q.-T., Gaudreau-Lapierre, A., Palii, C. G., Resende, V. M. F., Campuzano, D., Aeschimann, C. S., et al. (2020). A nuclear stress pathway that parallels cytoplasmic stress granule formation. iScience 23:101664.

Doan, N. T., Paulsen, E. S., Sehgal, P., Møller, J. V., Nissen, P., Denmeade, S. R., et al. (2015). Targeting thapsigargin towards tumors. Steroids 97, 2-7.

Dowling, R. J., Topisirovic, I., Fonseca, B. D., and Sonenberg, N. (2010). Dissecting the role of mTOR: lessons from mTOR inhibitors. Biochim. Biophys. Acta 1804, 433-439. doi: 10.1016/j.bbapap.2009.12.001

Eisinger-Mathason, T. S., Andrade, J., Groehler, A. L., Clark, D. E., MuratoreSchroeder, T. L., Pasic, L., et al. (2008). Codependent functions of RSK2 and the apoptosis-promoting factor TIA-1 in stress granule assembly and cell survival. Mol. Cell 31, 722-736. doi: 10.1016/j.molcel.2008.06.025

El-Naggar, A. M., and Sorensen, P. H. (2018). Translational control of aberrant stress responses as a hallmark of cancer. J. Pathol. 244, 650-666.

Fournier, M. J., Coudert, L., Mellaoui, S., Adjibade, P., Gareau, C., Côté, M. F., et al. (2013). Inactivation of the mTORC1-eukaryotic translation initiation factor 4E pathway alters stress granule formation. Mol. Cell. Biol. 33, 2285-2301. doi: 10.1128/MCB.01517-12

Fournier, M. J., Gareau, C., and Mazroui, R. (2010). The chemotherapeutic agent bortezomib induces the formation of stress granules. Cancer Cell Int. 10:12.

Frydryskova, K., Masek, T., Borcin, K., Mrvova, S., Venturi, V., and Pospisek, M. (2016). Distinct recruitment of human eIF4E isoforms to processing bodies and stress granules. BMC Mol. Biol. 17:21. doi: 10.1186/s12867-016-0072-x

Fujimura, K., Sasaki, A. T., and Anderson, P. (2012). Selenite targets eIF4E-binding protein-1 to inhibit translation initiation and induce the assembly of noncanonical stress granules. Nucleic Acids Res. 40, 8099-8110. doi: 10.1093/nar/ gks566

Fujiwara-Okada, Y., Matsumoto, Y., Fukushi, J., Setsu, N., Matsuura, S., Kamura, S., et al. (2013). Y-box binding protein-1 regulates cell proliferation and is associated with clinical outcomes of osteosarcoma. Br. J. Cancer 108, 836-847. doi: 10.1038/bjc.2012.579

Gao, J., Aksoy, B. A., Dogrusoz, U., Dresdner, G., Gross, B., Sumer, S. O., et al. (2013). Integrative analysis of complex cancer genomics and clinical profiles using the cBioPortal. Sci. Signal. 6:11.

Gao, X., Jiang, L., Gong, Y., Chen, X., Ying, M., Zhu, H., et al. (2019). Stress granule: a promising target for cancer treatment. Br. J. Pharmacol. 176, 4421-4433.

García, M. A., Gil, J., Ventoso, I., Guerra, S., Domingo, E., Rivas, C., et al. (2006). Impact of protein kinase PKR in cell biology: from antiviral to antiproliferative action. Microbiol. Mol. Biol. Rev. 70, 1032-1060. doi: 10.1128/MMBR. 00027-06

Gareau, C., Fournier, M. J., Filion, C., Coudert, L., Martel, D., Labelle, Y., et al. (2011). P21waf1/cip1 upregulation through the stress granule-associated protein CUGBP1 confers resistance to bortezomib-mediated apoptosis. PLoS One 6:e20254. doi: 10.1371/journal.pone.0020254

Gilks, N., Kedersha, N., Ayodele, M., Shen, L., Stoecklin, G., Dember, L. M., et al. (2004). Stress granule assembly is mediated by prion-like aggregation of TIA-1. Mol. Biol. Cell 15, 5383-5398. doi: 10.1091/mbc.e04-08-0715

Gottschald, O., Malec, V., Krasteva, G., Hasan, D., Subtil, F., Herold, S., et al. (2010). TIAR and TIA-1 mRNA-binding proteins co-aggregate under conditions of rapid oxygen decline and extreme hypoxia and suppress the HIF-1\{alpha\} pathway. J. Mol. Cell Biol. 2, 345-356. doi: 10.1093/jmcb/mjq032

Goulet, I., Boisvenue, S., Mokas, S., Mazroui, R., and Côté, J. (2008). TDRD3, a novel Tudor domain-containing protein, localizes to cytoplasmic stress granules. Hum. Mol. Genet. 17, 3055-3074.

Grabocka, E., and Bar-Sagi, D. (2016). Mutant KRAS enhances tumor cell fitness by upregulating stress granules. Cell 167, 1803-1813.e12. doi: 10.1016/j.cell.2016. 11.035

Guo, X., Wu, Y., and Hartley, R. S. (2010). Cold-inducible RNA-binding protein contributes to human antigen $\mathrm{R}$ and cyclin $\mathrm{E} 1$ deregulation in breast cancer. Mol. Carcinog. 49, 130-140. doi: 10.1002/mc.20582

Gupta, N., Badeaux, M., Liu, Y., Naxerova, K., Sgroi, D., Munn, L. L., et al. (2017). Stress granule-associated protein G3BP2 regulates breast tumor initiation. Proc. Natl. Acad. Sci. U.S.A. 114, 1033-1038.

Gutierrez-Beltran, E., Moschou, P. N., Smertenko, A. P., and Bozhkov, P. V. (2015). Tudor staphylococcal nuclease links formation of stress granules and processing bodies with mRNA catabolism in Arabidopsis. Plant Cell 27, 926-943. doi: $10.1105 /$ tpc. 114.134494

Haghandish, N., Baldwin, R. M., Morettin, A., Dawit, H. T., Adhikary, H., Masson, J. Y., et al. (2019). PRMT7 methylates eukaryotic translation initiation factor $2 \alpha$ and regulates its role in stress granule formation. Mol. Biol. Cell 30, 778-793. doi: 10.1091/mbc.E18-05-0330

Hamada, S., Matsumoto, R., Tanaka, Y., Taguchi, K., Yamamoto, M., and Masamune, A. (2021). Nrf2 activation sensitizes K-Ras mutant pancreatic cancer cells to glutaminase inhibition. Int. J. Mol. Sci. 22:1870. doi: 10.3390/ ijms 22041870

Hamidi, H., and Ivaska, J. (2018). Every step of the way: integrins in cancer progression and metastasis. Nat. Rev. Cancer 18, 533-548.

Hanahan, D., and Weinberg Robert, A. (2011). Hallmarks of cancer: the next generation. Cell 144, 646-674.

Heberle, A. M., Razquin Navas, P., Langelaar-Makkinje, M., Kasack, K., Sadik, A., Faessler, E., et al. (2019). The PI3K and MAPK/p38 pathways control stress granule assembly in a hierarchical manner. Life Sci. Alliance 2:e201800257. doi: 10.26508/lsa.201800257

Herman, A. B., Afonso, M. S., Kelemen, S. E., Ray, M., Vrakas, C. N., Burke, A. C., et al. (2019). Regulation of stress granule formation by inflammation, vascular injury, and atherosclerosis. Arterioscler. Thromb. Vasc. Biol. 39, 2014-2027. doi: 10.1161/ATVBAHA.119.313034

Hofmann, S., Cherkasova, V., Bankhead, P., Bukau, B., and Stoecklin, G. (2012) Translation suppression promotes stress granule formation and cell survival in response to cold shock. Mol. Biol. Cell 23, 3786-3800. doi: 10.1091/mbc.E1204-0296

Hofmann, S., Kedersha, N., Anderson, P., and Ivanov, P. (2021). Molecular mechanisms of stress granule assembly and disassembly. Biochim. Biophys. Acta Mol. Cell Res. 1868:118876.

Hsieh, A., Liu, Y., Edlind, M. P., Ingolia, N. T., Janes, M. R., Sher, A., et al. (2012). The translational landscape of mTOR signalling steers cancer initiation and metastasis. Nature 485, 55-61. doi: 10.1038/nature10912

Hwang, H. C., and Clurman, B. E. (2005). Cyclin E in normal and neoplastic cell cycles. Oncogene 24, 2776-2786.

Jevtov, I., Zacharogianni, M., van Oorschot, M. M., van Zadelhoff, G., AguileraGomez, A., Vuillez, I., et al. (2015). TORC2 mediates the heat stress response in Drosophila by promoting the formation of stress granules. J. Cell Sci. 128, 2497-2508. doi: 10.1242/jcs.168724

Johnson, M. E., Grassetti, A. V., Taroni, J. N., Lyons, S. M., Schweppe, D., Gordon, J. K., et al. (2016). Stress granules and RNA processing bodies are novel autoantibody targets in systemic sclerosis. Arthritis Res. Ther. 18:27. doi: 10.1186/s13075-016-0914-4

Kalkat, M., De Melo, J., Hickman, K. A., Lourenco, C., Redel, C., Resetca, D., et al. (2017). MYC deregulation in primary human cancers. Genes 8:151.

Kalra, J., Sutherland, B. W., Stratford, A. L., Dragowska, W., Gelmon, K. A., Dedhar, S., et al. (2010). Suppression of Her2/neu expression through ILK inhibition is regulated by a pathway involving TWIST and YB-1. Oncogene 29, 6343-6356. doi: 10.1038/onc.2010.366

Kano, S., Nishida, K., Kurebe, H., Nishiyama, C., Kita, K., Akaike, Y., et al (2014). Oxidative stress-inducible truncated serine/arginine-rich splicing factor 3 regulates interleukin-8 production in human colon cancer cells. Am. J. Physiol. Cell Physiol. 306, C250-C262. doi: 10.1152/ajpcell.00091.2013

Kashiwagi, S., Fujioka, Y., Kondo, T., Satoh, A. O., Yoshida, A., Fujioka, M., et al. (2019). Localization of BCR-ABL to stress granules contributes to its oncogenic function. Cell Struct. Funct. 44, 195-204. doi: 10.1247/csf.19033

Kedersha, N., Ivanov, P., and Anderson, P. (2013). Stress granules and cell signaling: more than just a passing phase? Trends Biochem. Sci. 38, 494-506. doi: 10.1016/j.tibs.2013.07.004

Khong, A., Matheny, T., Jain, S., Mitchell, S. F., Wheeler, J. R., and Parker, R. (2017) The stress granule transcriptome reveals principles of mRNA accumulation in stress granules. Mol. Cell 68, 808-20e5. doi: 10.1016/j.molcel.2017. 10.015

Khong, A., and Parker, R. (2018). mRNP architecture in translating and stress conditions reveals an ordered pathway of mRNP compaction. J. Cell Biol. 217, 4124-4140. doi: $10.1083 / j \mathrm{cb} .201806183$

Kim, W. J., Kim, J. H., and Jang, S. K. (2007). Anti-inflammatory lipid mediator 15d-PGJ2 inhibits translation through inactivation of eIF4A. EMBO J. 26, 5020-5032. doi: 10.1038/sj.emboj.7601920 
Krakhmal, N. V., Zavyalova, M. V., Denisov, E. V., Vtorushin, S. V., and Perelmuter, V. M. (2015). Cancer invasion: patterns and mechanisms. Acta Nat. 7, 17-28.

Krisenko, M. O., and Geahlen, R. L. (2015). Calling in SYK: SYK's dual role as a tumor promoter and tumor suppressor in cancer. Biochim. Biophys. Acta 1853, 254-263. doi: 10.1016/j.bbamcr.2014.10.022

Krisenko, M. O., Higgins, R. L., Ghosh, S., Zhou, Q., Trybula, J. S., Wang, W. H., et al. (2015). Syk is recruited to stress granules and promotes their clearance through autophagy. J. Biol. Chem. 290, 27803-27815. doi: 10.1074/jbc.M115. 642900

Kushwaha, D., O’Leary, C., Cron, K. R., Deraska, P., Zhu, K., D’Andrea, A. D., et al. (2015). USP9X inhibition promotes radiation-induced apoptosis in nonsmall cell lung cancer cells expressing mid-to-high MCL1. Cancer Biol. Ther. 16, 392-401. doi: 10.1080/15384047.2014.1002358

Levac, D., Colquhoun, H., and O’Brien, K. K. (2010). Scoping studies: advancing the methodology. Implement. Sci. 5:69.

Lim, H. J., Crowe, P., and Yang, J. L. (2015). Current clinical regulation of PI3K/PTEN/Akt/mTOR signalling in treatment of human cancer. J. Cancer Res. Clin. Oncol. 141, 671-689. doi: 10.1007/s00432-014-1803-3

Lin, C.-Y., Chang, J. S., Huang, S.-M., Hung, C.-J., Hung, C.-L., Chang, C.-T., et al. (2021). Experience of sorafenib treatment in differentiated thyroid cancer from Taiwan. J. Formos. Med. Assoc. 120(Pt 1), 189-195. doi: 10.1016/j.jfma.2020. 04.021

Lin, L., Li, X., Pan, C., Lin, W., Shao, R., Liu, Y., et al. (2019). ATXN2L upregulated by epidermal growth factor promotes gastric cancer cell invasiveness and oxaliplatin resistance. Cell Death Dis. 10:173. doi: 10.1038/s41419-019$1362-2$

Lin, Y., Protter, D. S., Rosen, M. K., and Parker, R. (2015). Formation and maturation of phase-separated liquid droplets by RNA-binding proteins. Mol. Cell 60, 208-219.

Liu, T. T., Arango-Argoty, G., Li, Z., Lin, Y., Kim, S. W., Dueck, A., et al. (2015). Noncoding RNAs that associate with YB-1 alter proliferation in prostate cancer cells. RNA (New York, NY). 21, 1159-1172. doi: 10.1261/rna.045559.114

Longley, D. B., Harkin, D. P., and Johnston, P. G. (2003). 5-fluorouracil: mechanisms of action and clinical strategies. Nat. Rev Cancer 3, 330-338.

Lovci, M. T., Ghanem, D., Marr, H., Arnold, J., Gee, S., Parra, M., et al. (2013). Rbfox proteins regulate alternative mRNA splicing through evolutionarily conserved RNA bridges. Nat. struct. Mol. Biol. 20, 1434-1442. doi: 10.1038/ nsmb.2699

Lu, L., Han, A. P., and Chen, J. J. (2001). Translation initiation control by hemeregulated eukaryotic initiation factor 2alpha kinase in erythroid cells under cytoplasmic stresses. Mol. Cell. Biol. 21, 7971-7980. doi: 10.1128/MCB.21.23. 7971-7980.2001

Mahboubi, H., and Stochaj, U. (2017). Cytoplasmic stress granules: dynamic modulators of cell signaling and disease. Biochim. Biophys. Acta Mol. Basis Dis. $1863,884-895$.

Malinovska, L., Kroschwald, S., and Alberti, S. (2013). Protein disorder, prion propensities, and self-organizing macromolecular collectives. Biochim. Biophys. Acta 1834, 918-931. doi: 10.1016/j.bbapap.2013.01.003

Mazloomian, A., Araki, S., Ohori, M., El-Naggar, A. M., Yap, D., Bashashati, A., et al. (2019). Pharmacological systems analysis defines EIF4A3 functions in cellcycle and RNA stress granule formation. Commun. Biol. 2:165. doi: 10.1038/ s42003-019-0391-9

Mazroui, R., Di Marco, S., Kaufman, R. J., and Gallouzi, I. E. (2007). Inhibition of the ubiquitin-proteasome system induces stress granule formation. Mol. Biol. Cell 18, 2603-2618.

Meng, X., Zhu, D., Yang, S., Wang, X., Xiong, Z., Zhang, Y., et al. (2012). Cytoplasmic Metadherin (MTDH) provides survival advantage under conditions of stress by acting as RNA-binding protein. J. Biol. Chem. 287, 4485-4491. doi: 10.1074/jbc.C111.291518

Miyoshi, M., Okajima, T., Matsuda, T., Fukuda, M. N., and Nadano, D. (2007). Bystin in human cancer cells: intracellular localization and function in ribosome biogenesis. Biochem. J. 404, 373-381. doi: 10.1042/BJ20061597

Mizushima, N., and Levine, B. (2010). Autophagy in mammalian development and differentiation. Nat. Cell Biol. 12, 823-830.

Mokas, S., Mills, J. R., Garreau, C., Fournier, M. J., Robert, F., Arya, P., et al. (2009). Uncoupling stress granule assembly and translation initiation inhibition. Mol. Biol. Cell 20, 2673-2683.
Morettin, A., Paris, G., Bouzid, Y., Baldwin, R. M., Falls, T. J., Bell, J. C., et al. (2017). Tudor domain containing protein 3 promotes tumorigenesis and invasive capacity of breast cancer cells. Sci. Rep. 7:5153.

Mukhopadhyay, S., Goswami, D., Adiseshaiah, P., Burgan, W., Yi, M., Guerin, T., et al. (2020). Undermining glutaminolysis bolsters chemotherapy while NRF2 promotes chemoresistance in KRAS-driven pancreatic cancers. Cancer Res. 80, 1630-1643. doi: 10.1158/0008-5472.CAN-19-1363

Namkoong, S., Ho, A., Woo, Y. M., Kwak, H., and Lee, J. H. (2018). Systematic characterization of stress-induced RNA granulation. Mol. Cell 70, 175-187.e8. doi: 10.1016/j.molcel.2018.02.025

Narayanan, N., Wang, Z., Li, L., and Yang, Y. (2017). Arginine methylation of USP9X promotes its interaction with TDRD3 and its anti-apoptotic activities in breast cancer cells. Cell Discov. 3:16048. doi: 10.1038/celldisc.2016.48

Nikpour, P., Baygi, M. E., Steinhoff, C., Hader, C., Luca, A. C., Mowla, S. J., et al. (2011). The RNA binding protein Musashil regulates apoptosis, gene expression and stress granule formation in urothelial carcinoma cells. J. Cell. Mol. Med. 15, 1210-1224. doi: 10.1111/j.1582-4934.2010.01090.x

Palangi, F., Samuel, S. M., Thompson, I. R., Triggle, C. R., and Emara, M. M. (2017). Effects of oxidative and thermal stresses on stress granule formation in human induced pluripotent stem cells. PLoS One 12:e0182059. doi: 10.1371/journal. pone. 0182059

Park, S. H., Choi, H. J., Yang, H., Do, K. H., Kim, J., Kim, H. H., et al. (2012). Two in-and-out modulation strategies for endoplasmic reticulum stress-linked gene expression of pro-apoptotic macrophage-inhibitory cytokine 1. J. Biol. Chem. 287, 19841-19855. doi: 10.1074/jbc.M111.330639

Pizzo, E., Sarcinelli, C., Sheng, J., Fusco, S., Formiggini, F., Netti, P., et al. (2013). Ribonuclease/angiogenin inhibitor 1 regulates stress-induced subcellular localization of angiogenin to control growth and survival. J. Cell Sci. 126(Pt 18), 4308-4319. doi: $10.1242 /$ jcs. 134551

Podszywalow-Bartnicka, P., Wolczyk, M., Kusio-Kobialka, M., Wolanin, K., Skowronek, K., Nieborowska-Skorska, M., et al. (2014). Downregulation of brcal protein in bcr-abll leukemia cells depends on stress-triggered tiarmediated suppression of translation. Cell Cycle 13, 3727-3741. doi: 10.4161/ 15384101.2014.965013

Protter, D. S. W., and Parker, R. (2016). Principles and properties of stress granules. Trends Cell Biol. 26, 668-679.

Qiang, Y.-W., Ye, S. Q., Chen, Y., Epstein, J., Davies, F., Morgan, G., et al. (2019). Mutant KRAS enhances stress granules and resistance to proteasome inhibition via 15-d-PGJ2 in multiple myeloma. Blood 134:4383.

Salminen, A., Kaarniranta, K., and Kauppinen, A. (2013). Beclin 1 interactome controls the crosstalk between apoptosis, autophagy and inflammasome activation: impact on the aging process. Ageing Res. Rev. 12, 520-534. doi: 10.1016/j.arr.2012.11.004

Samanta, T., and Kar, S. (2021). Unraveling the origin of glucose mediated disparate proliferation dynamics of cancer stem cells. J. Theor. Biol. 526:110774. doi: 10.1016/j.jtbi.2021.110774

Sanchez-Vega, F., Mina, M., Armenia, J., Chatila, W. K., Luna, A., La, K. C., et al. (2018). Oncogenic signaling pathways in the cancer genome atlas. Cell 173, 321-337.e10.

Schewe, D. M., and Aguirre-Ghiso, J. A. (2009). Inhibition of eIF2alpha dephosphorylation maximizes bortezomib efficiency and eliminates quiescent multiple myeloma cells surviving proteasome inhibitor therapy. Cancer Res. 69, 1545-1552. doi: 10.1158/0008-5472.CAN-08-3858

Senft, D., and Ronai, Z. E. (2016). Adaptive stress responses during tumor metastasis and dormancy. Trends Cancer 2, 429-442.

Sfakianos, A., Mellor, L., Pang, Y., Kritsiligkou, P., Needs, H., Abou-Hamdan, H., et al. (2018). The mTOR-S6 kinase pathway promotes stress granule assembly. Cell Death Differ. 25, 1766-1780.

Sharma, D. K., Bressler, K., Patel, H., Balasingam, N., and Thakor, N. (2016). Role of eukaryotic initiation factors during cellular stress and cancer progression. J. Nucleic Acids 2016:8235121.

Shelton, L. M., Mukherjee, P., Huysentruyt, L. C., Urits, I., Rosenberg, J. A., and Seyfried, T. N. (2010). A novel pre-clinical in vivo mouse model for malignant brain tumor growth and invasion. J. Neuro Oncol. 99, 165-176.

Somasekharan, S. P., El-Naggar, A., Leprivier, G., Cheng, H., Hajee, S., Grunewald, T. G., et al. (2015). YB-1 regulates stress granule formation and tumor progression by translationally activating G3BP1. J. Cell Biol. 208, 913-929. doi: $10.1083 /$ jcb.201411047 
Szafron, L. M., Balcerak, A., Grzybowska, E. A., Pienkowska-Grela, B., FelisiakGolabek, A., Podgorska, A., et al. (2015). The novel gene CRNDE encodes a nuclear peptide (CRNDEP) which is overexpressed in highly proliferating tissues. PLoS One 10:e0127475. doi: 10.1371/journal.pone.0127475

Takahara, T., and Maeda, T. (2012). Transient sequestration of TORC1 into stress granules during heat stress. Mol. Cell 47, 242-252. doi: 10.1016/j.molcel.2012. 05.019

Takayama, K. I., Suzuki, T., Fujimura, T., Takahashi, S., and Inoue, S. (2018). Association of USP10 with G3BP2 inhibits p53 signaling and contributes to poor outcome in prostate cancer. Mol. Cancer Res. 16, 846-856. doi: 10.1158/ 1541-7786.MCR-17-0471

Taniuchi, K., Furihata, M., and Saibara, T. (2014). KIF20A-mediated RNA granule transport system promotes the invasiveness of pancreatic cancer cells. Neoplasia (New York, NY) 16, 1082-1093. doi: 10.1016/j.neo.2014.10.007

Taniuchi, K., Nishimori, I., and Hollingsworth, M. A. (2011a). Intracellular CD24 inhibits cell invasion by posttranscriptional regulation of BART through interaction with G3BP. Cancer Res. 71, 895-905. doi: 10.1158/0008-5472.CAN$10-2743$

Taniuchi, K., Nishimori, I., and Hollingsworth, M. A. (2011b). The N-terminal domain of G3BP enhances cell motility and invasion by posttranscriptional regulation of BART. Mol. Cancer Res. 9, 856-866. doi: 10.1158/1541-7786. MCR-10-0574

Tao, S., Wang, S., Moghaddam, S. J., Ooi, A., Chapman, E., Wong, P. K., et al. (2014). Oncogenic KRAS confers chemoresistance by upregulating NRF2. Cancer Res. 74, 7430-7441.

Tarin, D. (2011). Cell and tissue interactions in carcinogenesis and metastasis and their clinical significance. Semin. Cancer Biol. 21, 72-82.

Thedieck, K., Holzwarth, B., Prentzell, M. T., Boehlke, C., Kläsener, K., Ruf, S., et al. (2013). Inhibition of mTORC1 by astrin and stress granules prevents apoptosis in cancer cells. Cell 154, 859-874. doi: 10.1016/j.cell.2013.07.031

Tricco, A. C., Lillie, E., Zarin, W., O'Brien, K. K., Colquhoun, H., Levac, D., et al. (2018). PRISMA extension for scoping reviews (PRISMA-ScR): checklist and explanation. Ann. Intern. Med. 169, 467-473.

Unni, N., and Arteaga, C. L. (2019). Is dual mTORC1 and mTORC2 therapeutic blockade clinically feasible in cancer? JAMA Oncol. 5, 1564-1565. doi: 10.1001/ jamaoncol.2019.2525

Unworth, H., Raguz, S., Edwards, H. J., Higgins, C. F., and Yagüe, E. (2010). mRNA escape from stress granule sequestration is dictated by localization to the endoplasmic reticulum. FASEB J. 24, 3370-3380.

Urra, H., Dufey, E., Avril, T., Chevet, E., and Hetz, C. (2016). Endoplasmic reticulum stress and the hallmarks of cancer. Trends Cancer 2, 252-262.

Valentin-Vega, Y. A., Wang, Y. D., Parker, M., Patmore, D. M., Kanagaraj, A., Moore, J., et al. (2016). Cancer-associated DDX3X mutations drive stress granule assembly and impair global translation. Sci. Rep. 6:25996. doi: 10.1038/ srep25996

Vellky, J. E., McSweeney, S. T., Ricke, E. A., and Ricke, W. A. (2020). RNAbinding protein DDX3 mediates posttranscriptional regulation of androgen receptor: a mechanism of castration resistance. Proc. Natl. Acad. Sci. U.S.A. 117, 28092-28101. doi: 10.1073/pnas.2008479117

Wall, M. L., and Lewis, S. M. (2017). Methylarginines within the RGG-Motif Region of hnRNP Al affect its IRES trans-acting factor activity and are required for hnRNP A1 stress granule localization and formation. J. Mol. Biol. 429, 295-307. doi: 10.1016/j.jmb.2016.12.011

Wang, R., Cao, L., Thorne, R. F., Zhang, X. D., Li, J., Shao, F., et al. (2021). LncRNA GIRGL drives CAPRIN1-mediated phase separation to suppress glutaminase1 translation under glutamine deprivation. Sci. Adv. 7:eabe5708. doi: 10.1126/ sciadv.abe5708

Wang, R., Jiang, X., Bao, P., Qin, M., and Xu, J. (2019). Circadian control of stress granules by oscillating EIF2 $\alpha$. Cell Death Dis. 10:215.

Wang, Y., Fu, D., Chen, Y., Su, J., Wang, Y., Li, X., et al. (2018). G3BP1 promotes tumor progression and metastasis through IL-6/G3BP1/STAT3 signaling axis in renal cell carcinomas. Cell Death Dis. 9:501. doi: 10.1038/s41419-018-0504-2

Weeks, A., Agnihotri, S., Lymer, J., Chalil, A., Diaz, R., Isik, S., et al. (2016). Epithelial cell transforming 2 and aurora kinase B modulate formation of stress granule-containing transcripts from diverse cellular pathways in astrocytoma cells. Am. J. Pathol. 186, 1674-1687. doi: 10.1016/j.ajpath.2016.02.013

Weiss, J. M. (2020). The promise and peril of targeting cell metabolism for cancer therapy. Cancer Immunol Immunother. 69, 255-261.
Wek, S. A., Zhu, S., and Wek, R. C. (1995). The histidyl-tRNA synthetase-related sequence in the eIF-2 alpha protein kinase GCN2 interacts with tRNA and is required for activation in response to starvation for different amino acids. Mol. Cell. Biol. 15, 4497-4506. doi: 10.1128/MCB.15.8.4497

Wen, F., Zhou, R., Shen, A., Choi, A., Uribe, D., and Shi, J. (2012). The tumor suppressive role of eIF3f and its function in translation inhibition and rRNA degradation. PLoS One 7:e34194. doi: 10.1371/journal.pone.0034194

Wheeler, J. R., Matheny, T., Jain, S., Abrisch, R., and Parker, R. (2016). Distinct stages in stress granule assembly and disassembly. Elife 5:e18413. doi: 10.7554/ eLife. 18413

Wippich, F., Bodenmiller, B., Trajkovska, M. G., Wanka, S., Aebersold, R., and Pelkmans, L. (2013). Dual specificity kinase DYRK3 couples stress granule condensation/dissolution to mTORC1 signaling. Cell 152, 791-805. doi: 10. 1016/j.cell.2013.01.033

Wolfson, R. L., and Sabatini, D. M. (2017). The dawn of the age of amino acid sensors for the mTORC1 pathway. Cell metabolism. 26, 301-309. doi: 10.1016/ j.cmet.2017.07.001

Wolozin, B., and Ivanov, P. (2019). Stress granules and neurodegeneration. Nat. Rev. Neurosci. 20, 649-666.

Xiong, R., Gao, J. L., and Yin, T. (2019). G3BP1 activates the TGF- $\beta /$ Smad signaling pathway to promote gastric cancer. Onco Targets Ther. 12, 7149-7156.

Yang, P., Mathieu, C., Kolaitis, R.-M., Zhang, P., Messing, J., Yurtsever, U., et al. (2020). G3BP1 is a tunable switch that triggers phase separation to assemble stress granules. Cell 181, 325-345.e28. doi: 10.1016/j.cell.2020. 03.046

Yang, X., Hu, Z., Fan, S., Zhang, Q., Zhong, Y., Guo, D., et al. (2018). Picornavirus 2A protease regulates stress granule formation to facilitate viral translation. PLoS Pathog. 14:e1006901. doi: 10.1371/journal.ppat.1006901

Yuan, L., Xiao, Y., Zhou, Q., Yuan, D., Wu, B., Chen, G., et al. (2014). Proteomic analysis reveals that MAEL, a component of nuage, interacts with stress granule proteins in cancer cells. Oncol. Rep. 31, 342-350. doi: 10.3892/or.2013. 2836

Zhang, Y., Yue, C., Anna, K., and Garkavtsev, I. (2021). Repression of the stress granule protein G3BP2 inhibits immune checkpoint molecule PD-L1. Mol. Oncol. doi: 10.1002/1878-0261.12915 [Epub ahead of print].

Zhao, J., Fu, X., Chen, H., Min, L., Sun, J., Yin, J., et al. (2021). G3BP1 interacts with YWHAZ to regulate chemoresistance and predict adjuvant chemotherapy benefit in gastric cancer. Br. J. Cancer 124, 425-436. doi: 10.1038/s41416-02001067-1

Zheng, H., Zhan, Y., Zhang, Y., Liu, S., Lu, J., Yang, Y., et al. (2019). Elevated expression of G3BP1 associates with $\mathrm{YB} 1$ and $\mathrm{p}-\mathrm{AKT}$ and predicts poor prognosis in nonsmall cell lung cancer patients after surgical resection. Cancer Med. 8, 6894-6903. doi: 10.1002/cam4.2579

Zhu, K., Liu, Q., Yubo, Z., Tao, C., Zhao, Z., Sun, J., et al. (2015). Oncogenes and tumor suppressor genes: comparative genomics and network perspectives. $B M C$ Genomics 16(Suppl. 7):S8. doi: 10.1186/1471-2164-16-S7-S8

Zou, T., Rao, J. N., Liu, L., Xiao, L., Cui, Y. H., Jiang, Z., et al. (2012). Polyamines inhibit the assembly of stress granules in normal intestinal epithelial cells regulating apoptosis. Am. J. Physiol. Cell Physiol. 303, C102-C111. doi: 10.1152/ ajpcell.00009.2012

Conflict of Interest: The authors declare that the research was conducted in the absence of any commercial or financial relationships that could be construed as a potential conflict of interest.

Publisher's Note: All claims expressed in this article are solely those of the authors and do not necessarily represent those of their affiliated organizations, or those of the publisher, the editors and the reviewers. Any product that may be evaluated in this article, or claim that may be made by its manufacturer, is not guaranteed or endorsed by the publisher.

Copyright $\odot 2021$ Asadi, Rahmanpour, Moslehian, Sabaie, Hassani, Ghafouri-Fard, Taheri and Rezazadeh. This is an open-access article distributed under the terms of the Creative Commons Attribution License (CC BY). The use, distribution or reproduction in other forums is permitted, provided the original author(s) and the copyright owner(s) are credited and that the original publication in this journal is cited, in accordance with accepted academic practice. No use, distribution or reproduction is permitted which does not comply with these terms. 